\title{
THE POSITION OF THE UNITED STATES OF AMERICA ON IRAQ'S ENTRY INTO THE LEAGUE OF NATIONS IN 1932
}

\author{
Ilham Mahmoud JADER ${ }^{1}$ \\ Rawaa Sabahh GANNAWI ${ }^{2}$
}

\section{Istanbul / Türkiye}

p. $616-634$

Received: $18 / 11 / 2021$

Accepted: 04/12/2021

Published: 01/01/2022

This article has been scanned I iThenticat No plagiarism detected

\begin{abstract}
:
The Iraqi government signed with Britain a treaty in $1930 \mathrm{AD}$, which approved a bilateral alliance between them that includes all political, economic and military issues, which will be recognized after Iraq's entry into the League of Nations. Iraq by entering the League and declaring his independence After the discussions, statements, and opinions that were presented at the meeting, the League's Mandates Committee announced on October 3, 1932, that Iraq had been accepted as a member of the League of Nations The independence of Iraq and its entry into the League of Nations is an important and pivotal issue, as Iraq became the first Arab country to get rid of the occupation, even though the independence was not complete because Britain sought to achieve this goal in exchange for a treaty that chained Iraq with many restrictions, including military and economic issues The United States of America has striven to develop its diplomatic relations with Iraq, given that Iraq was of strategic importance in the eyes of American policy planners. US to the level of an embassy in Baghdad The cultural relations between Iraq and the United States during the royal era developed significantly if compared to other fields, because it is considered the gateway to Iraq's entry to the League of Nations, and for this reason the Iraqi government set up in 1930 a committee of experts to improve education and recommended the necessity of adopting the American approach to education, and this The Americans wanted to exploit it after they had a share in Iraq's oil, and thus exploiting all means in order to secure their interests, especially the means of education, because it is an effective means in creating a trend of educated elites tending to the United States of America.
\end{abstract}

Key words: Political, Nations, Independence.

http: //dx.doi.org/10.47832/2717-8293.15.43

Dr. ,Kufa University,Iraq, ilhamm.kadhim@uokufa.edu.iq, ,https: //orcid.org/0000-0002-2704-4746

2 ID Reasearcher, Kufa University,Iraq, „rawaa.gannawi@uokufa.edu.iq,https//orcid.org/0000-0002-0940-4066 


\title{
دور الولايات المتحدة الأمريكية في دخول العراق عصبة الأمم عام 1932
}

\author{
3 إلهام محمود الجحادر \\ رواء صباح كناوي
}

وقعت الحكومة العراقية مع بريطانيا معاهدة عام 1930م والتي أقرت عقد تحالف ثنائي بينهما يشمل جميع المسائل السياسية والاقتصادية والعسكرية، يتم الاعتراف بها بعد دخول العراق عضوا في عصبة الأمم، ولتحقيق ذلك قدمت بريطانيا تقريرها بهذا

الخصوص إلى لجنة الانتدابات في العصبة لاتخاذ قرار الموافقة على طلب الحكومة العراقية بدخوله العصبة وإعلان استقلاله.

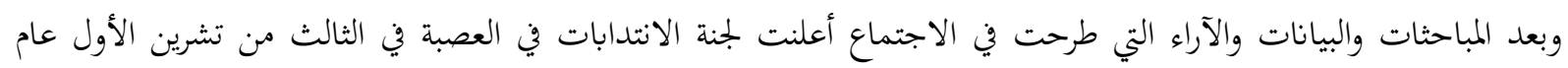
1932م قبول العراق عضوا في عصبة الأمم. إن استقلال العراق ودخوله عضوا في عصبة الأمم قضية مهمة ومحورية إذ أصبح العراق أول دولة عربية تتخلص من الاحتلال، رغم

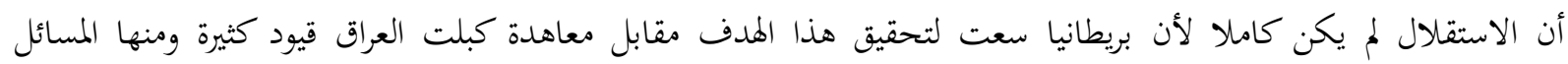
العسكرية والاقتصادية.

وسعت الولايات المتحدة الأمريكية حثيثاً من أجل تطوير علاقاتما الدبلوماسية مع العراق، لما كان للعراق من أهمية استراتيجية في

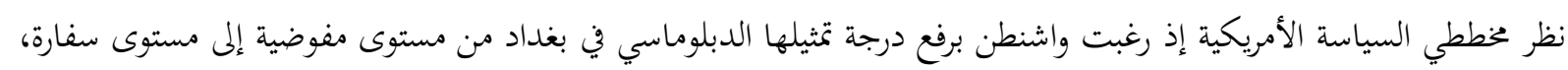

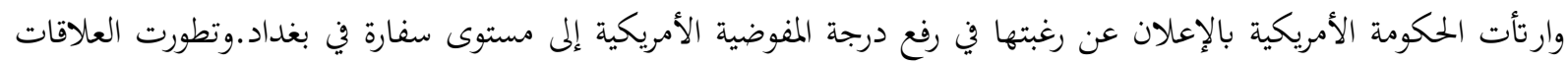

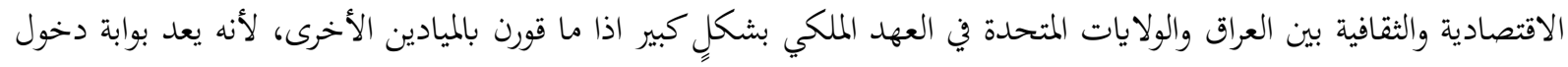

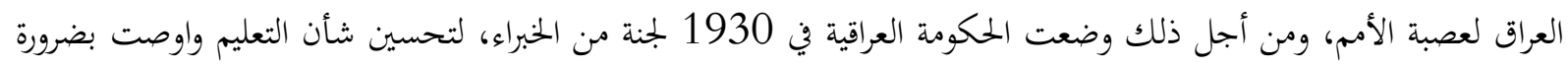

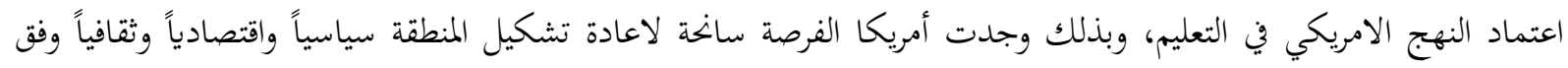

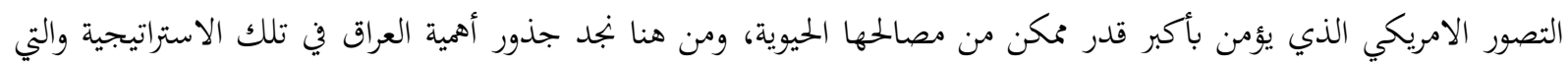
رسمت ملامح جديدة للعراق بما يتلائم وطموحاتما. الكلمات المفتاحية: الولايات المتحدة، عصبة الأمم، الدبلوماسية.

ازدادت أهمية العراق الاستراتيجية مع مطلع القرن العشرين، لاسيما مع تصاعد الصراعات السياسية والاقتصادية العالمية

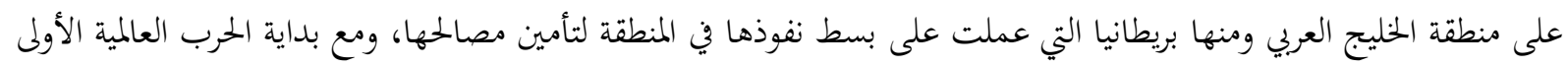

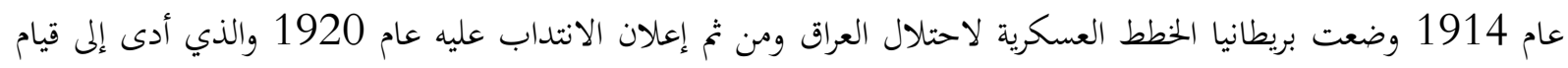

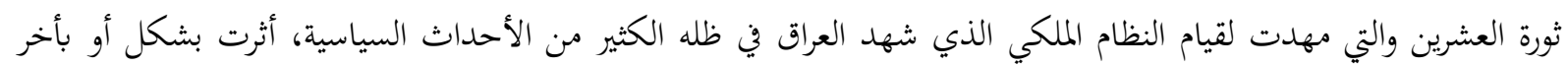

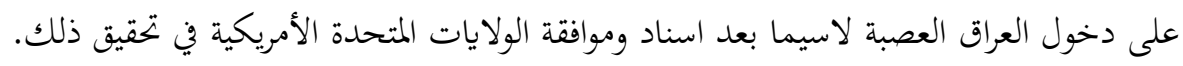

من هنا جاءت فكرة عنوان الدراسة، أما السبب في اختيار الموضوع الرغبة الشخصية لدراسة تاريخ العراق المعاصر وأهمية

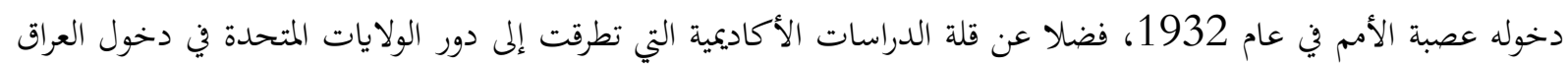


العصبة. ومن أهم أهداف الدراسة توضيح دور بريطانيا في ترشيح العراق عضوا في عصبة الأمم، وموقف الولايات المتحدة

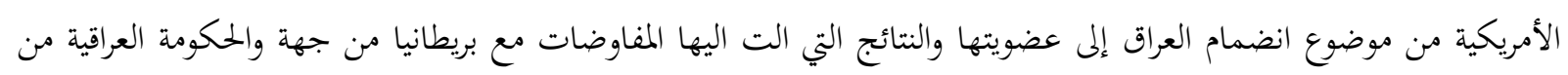
جهة أخرى. 


\section{المبحث الأول: ترشيح بريطانيا العراق كعضو في عصبة الأمم وإعلان استقلاله.}

تركزت مطالب الثعب العراقي منذ قيام الحكم الملكي على إهاء الانتداب ودخول العراق عصبة الأمم ونتيجة للتطورات

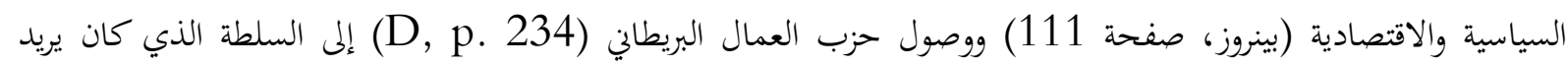

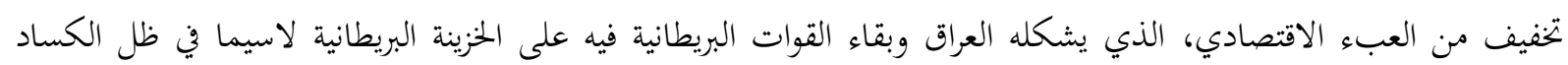
الكبير، الذي ضرب الاقتصاد العالمي حينها و تأثر بريطانيا به كثيراً.

طلبت الحكومة البريطانية من المندوب السامي البريطاني الجديد جلبرت كلايتون (السامرائي، 2015، صفحة 113) والذي وصل إلى العراق في 2 آذار 1929م و كاب مان متعاطفا مع المطالب العراقية، أن يعلم الملك فيصل (Clbert Clayton) الاول (اللطيف، 1911، الصفحات 10-15) والحكومة العراقية عن رغبة بريطانيا لإهاء الانتداب وترشيح العراق لعضوية

$$
\text { عصبة الأمم (العمر، 1977، صفحة 260). }
$$

جرت مفاوضات بين الطرفين لعقد معاهدة التحالف بدأت في 21أذار 1930م وقد ترأس الوفد البريطاني المندوب

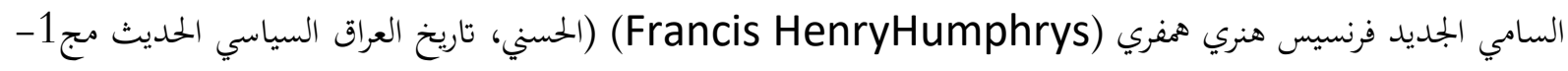

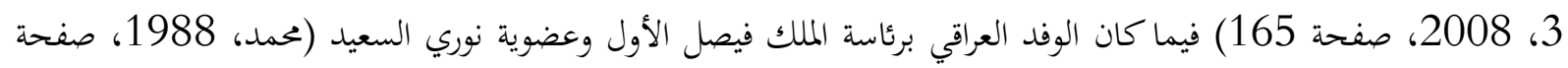

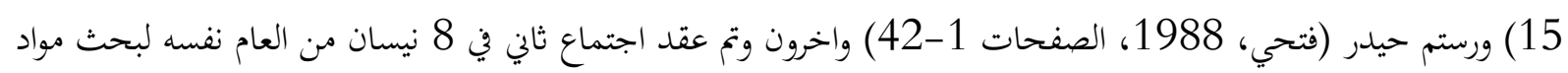

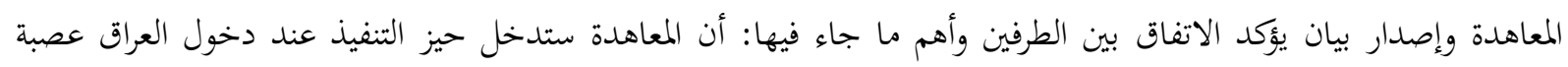
الأمم ويكون وضعه دولة حرة مستقلة، و ألحقت بالمعاهدة بنود منها أن تسري لمدة 25 عام (معهد القائد المؤسس للدراس المعاسات

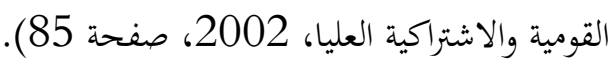

تعد معاهدة 1930من أهم المعاهدات التي عقدت بين العراق وبريطانيا، فعلى المستوى الداخلي فأها ألغت الانتداب

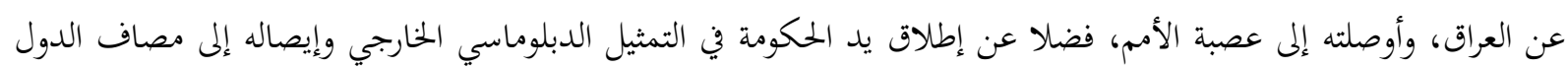

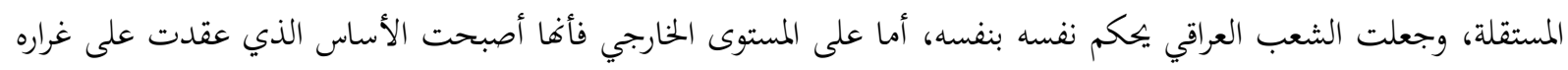

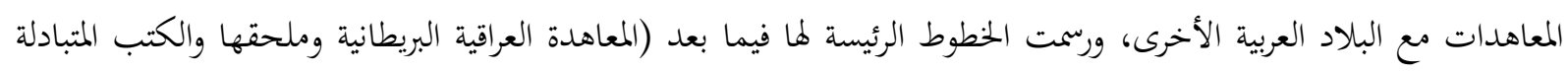

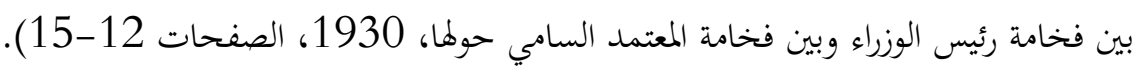
أشعرت الحكومة البريطانية عصبة الأمم في عام 1929، بعزمها على ترشيح العراق لعضوية عصبة الأمم إذا ما حل عام

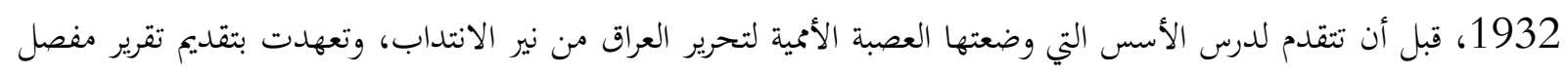

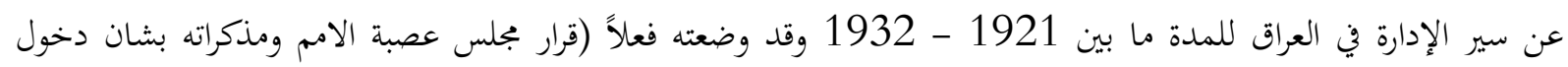
العراق عصبة الامم في اجتماعه المنعقد في 28 كانون الثاني 1932، 1932 1932، الصفحات لإندات 12-15) وقدم ممثل الحكومة البريطانية في العصبة اللورد سيسل (Cecil) (حمدان، 2013، صفحة 118) نسخة منه إلى

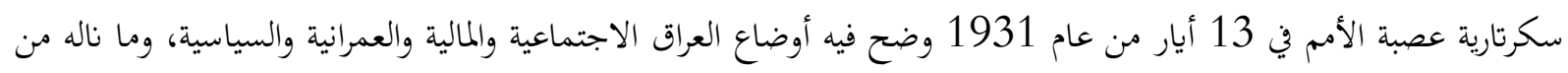

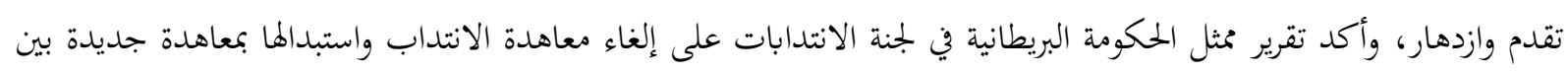
العراق وبريطانيا كبلدين مستقلين حليفين عبر تشكيل حلف وثيق ترسيخا للصداقة بينهما وإجراء تشاور صريح في كل قضائ قضاياه

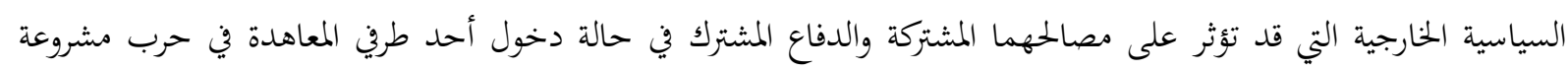
قانونياً أو التعرض إلى التهديد المباشر بها، إذ نصت على أنى أن يهب الطرف الآخر للدفاع عنهاع.

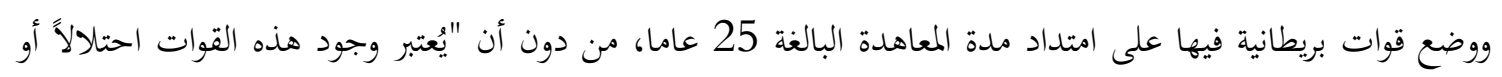

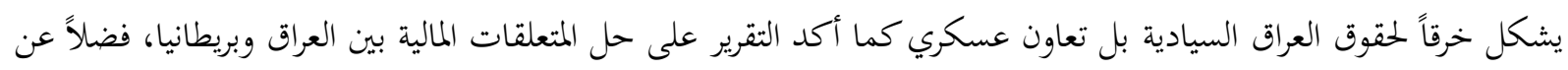


اتفاقية عدلية للتعاطي مع تحديات الثقة بالقضاء العراقي حينها (قرار مجلس عصبة الامم ومذكراته بشان دخول العراق عصبة الامم، الصفحات 15-16).

وتضمن التقرير أيضا على إلغاء كل الصلاحيات الانتدابية البريطانية في العراق، وحولتها للحكومة العراقية (أي السيادة

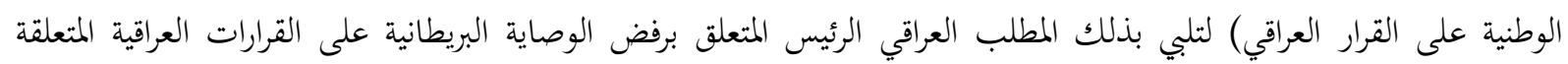

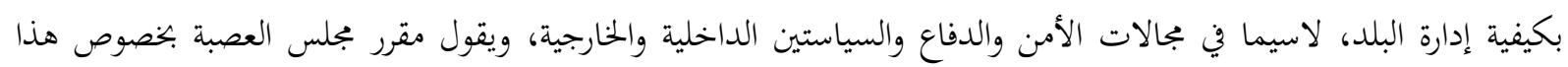

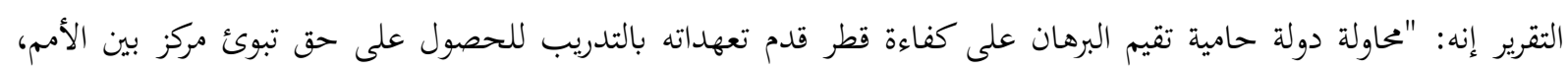

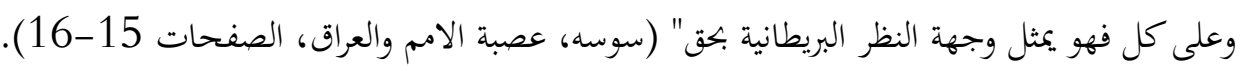

طلب المجلس في اليوم الرابع من شهر كانون الأول 1931م إلى اللجنة الدائمة للانتدابات أن تبدي رأيها في مقترح

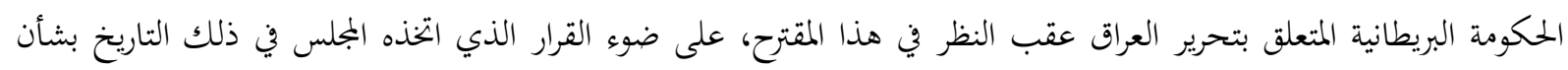

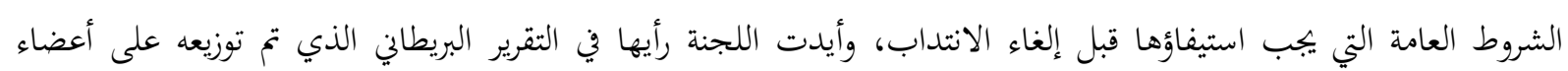

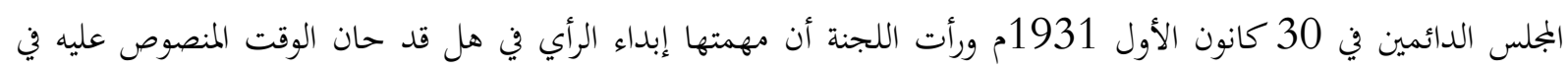

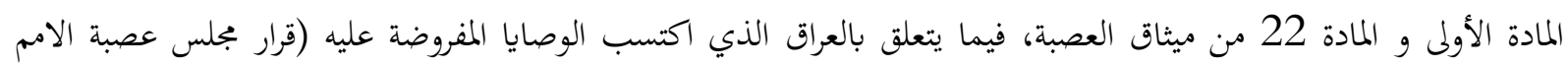

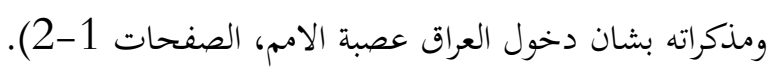
وبناء على طلب مجلس العصبة، رفع نائب رئيس لجنة الانتدابات السيد فان ريس (Van Race) (رباط، 2010، صفحة 15) تقريره ومن أهم ما جاء فيه: أنه يقتضي النظر في أمر انضمام العراق إلى عصبة الأمم إلى المادة الأولى والمادة الثانية

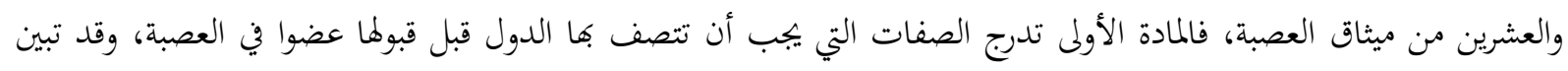

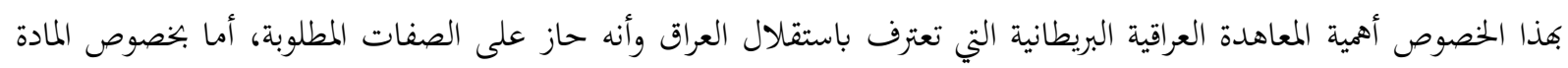

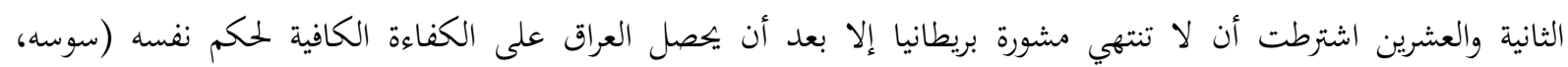

الصفحات 15-16).

وأشار نائب رئيس لجنة الانتدابات فان ريس أيضا في تقريره أن أمر دخول العراق عضوا في العصبة أدا أكدت الدولة

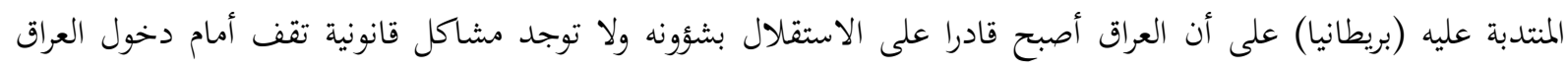

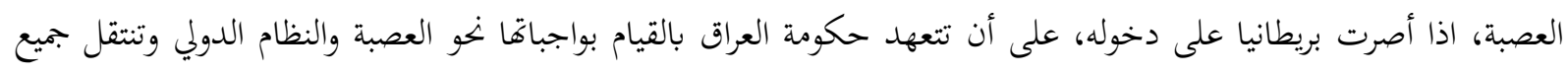

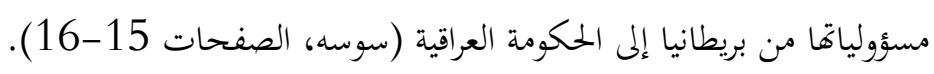
ولم تتمكن اللجنة في بادئ الأمر التوصل إلى نتيجة لأها لم تراقب أحوال العراق السياسية والداخلية عن قرب، وهذا هو

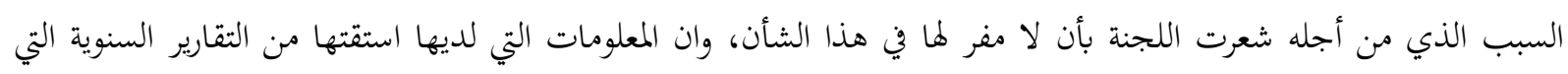

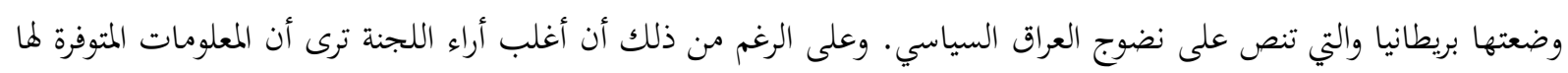

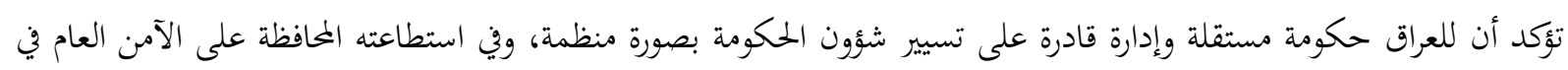
العراق وأثبتت أن لدى العراق مصادر مالية وافية لسد حاجات الحكومة، فضلا عن اعتماد قوانين ونظام قضائي فيها (طقوش،

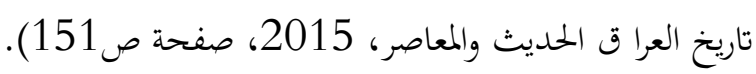

تولت لجنة الانتدابات الدائمة في عصبة الأمم فحص تقرير الحكومة البريطانية المنتدبة ممثلاً لاستجوابه، فأضاف هذا الممثل

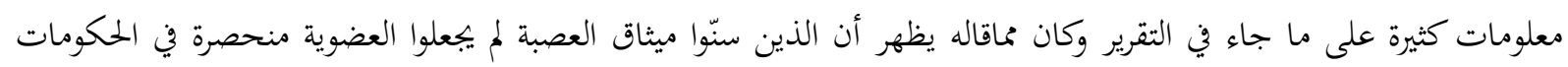

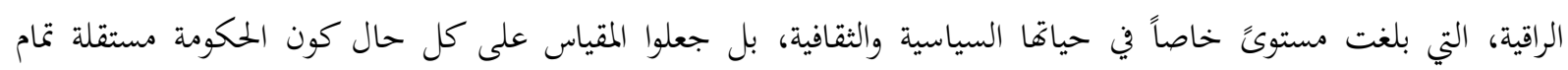
الاستقلال، وقادرة على أن تقف وحدها والدفاع عن نفسها. 


\section{قرار العصبة: - م}

استمر النقاش والسؤال والجواب طويلا ثم اتخذ مجلس العصبة هذا القرار لما كان المجلس مكلفا بالنظر في القضية الخاصة

المتعلقة بإلغاء الانتداب المفروض على العراق لذلك قرر المجلس الأمور التالية: (قرار مجلس عصبة الامم ومذكراته، صفحة 9).

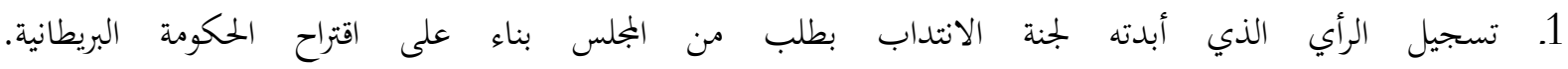
2. اعتماد المعلومات المتيسرة كافة للدلالة على أن العراق بوجه الإجمال قد استوفى الشروط الحقيقية المذكورة في ملحق القرار الذي الذي اتخذه المجلس في 4 أيلول عام 1931.

3. التصريح باستعداده مبدئيا للحكم بانقضاء عهد الانتداب في العراق، عندما تتعهد هذه الدولة أمام المجلس بعهود تنطبق على

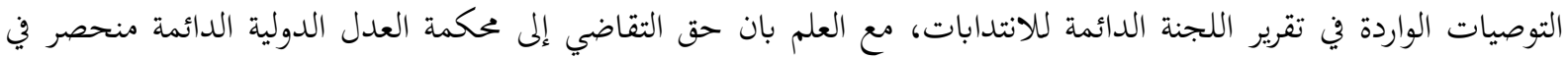
الأعضاء الذين لهم ممثلون في مجلس العصبة.

4. لذلك يطلب المجلس إلى مقريه لمسائل الأقليات والقانون الدولي والانتدابات وممثل بريطانيا العظمى في المجلس أن يهيئوا باستشارة ممثل الحكومة العراقية وعند الاقتضاء باستشارة مثثلي اللجنة الدائمة للانتدابات، لائحة تصريح تتناول شتى الضمانات الموصى بها في تقرير اللجنة الدائمة للانتدابات، وعرض تلك اللائحة على المجلس في دورته التالية. 5. أنه اذا حكم المجلس (بعد فحص العهود التي تقطعها الحكومة العراقية) بتقليص الانتداب عن العراق، ينفذ هذا الحكم ابتداء

$$
\text { من تاريخ انضمام العراق إلى عصبة الأمم. }
$$

هيأت اللجنة المختصة في عصبة الأمم مذكرتين مختصرتين بالشروط المطلوبة من العراق ضماناً لانخراطه في عضوية العصبة

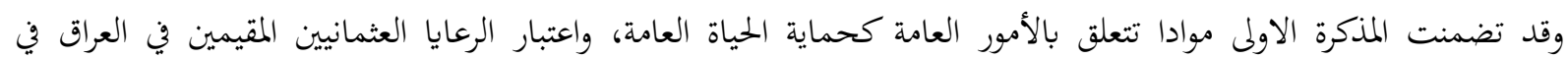
السادس من آب 1924 قد اكتسبوا الجنسية العراقية يتمتعون بحقوق متساوية مدنية كانت هذه الحقوق ام سياسية ام دينية، وكانت كل هذه الامور مدرجة في القانون الاساسي العراقي.

أما المذكرة الثانية فهي تقتصر على مصالح الاجانب وبعض الامتيازات الدولية كالسماح للبعثات الدينية، من جميع المذاهب، بحرية التبشير والتدريس والتطبيب وغير ذلك، وان يعتبر العراق مقيدا بالمعاهدات والاتفاقات التي كانت دولة الانتداب

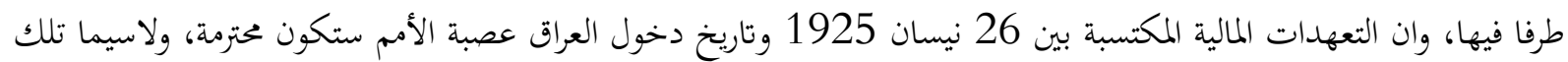

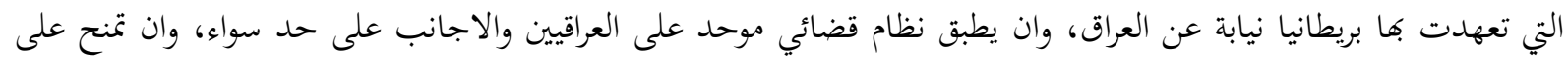

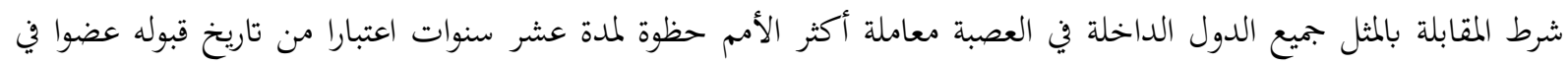

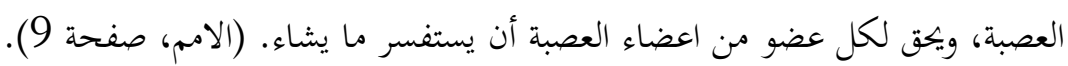




\section{المبحث الثاين: بدايات الوجود الامريكي في العراق}

من خلال استقراء التاريخ للعلاقات الأمريكية - العراقية وما أفرزته تفاعلاتما من احداث وسلوكيات، نجد أن الولايات

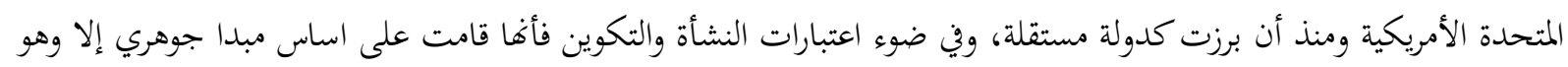

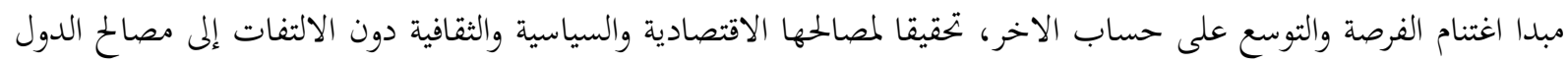

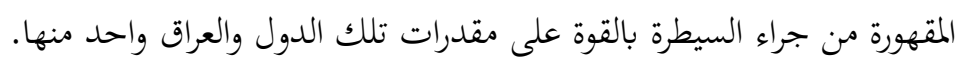
ولم يخف على الولايات المتحدة الأمريكية الاهمية الكبرى التي تشكلها بحيرة النفط التي يعوم عليها العراق ودول الخليج

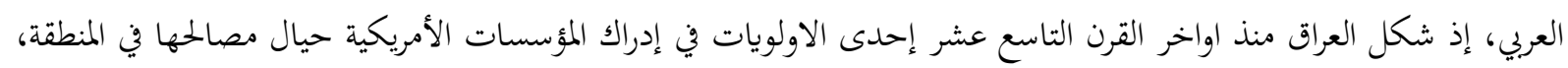

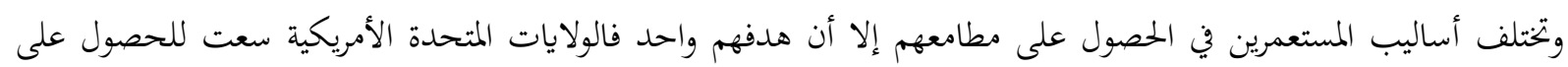

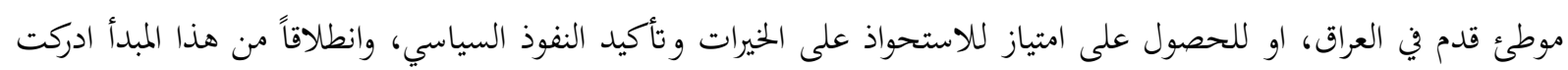

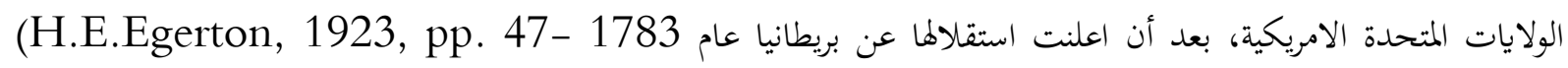

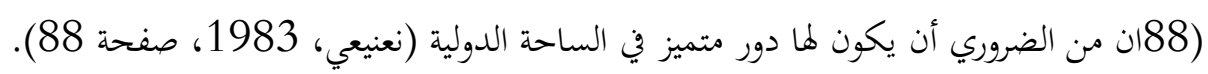
استخدمت حكومة الولايات المتحدة الأمريكية أساليب عدة لاستعمار الشعوب واستغلالما، فكانت أساليب هم

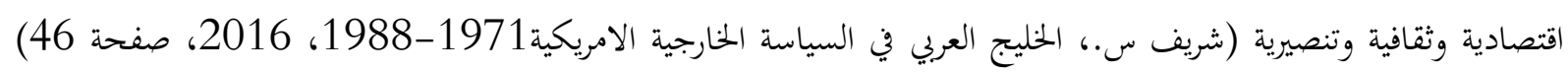

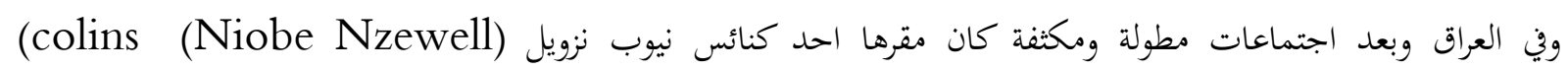
conices Encyclopedia, 1985, p. 473)

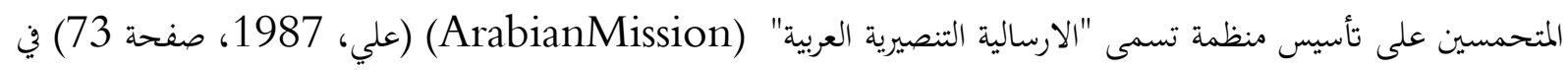

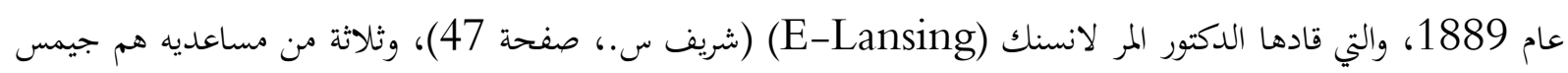

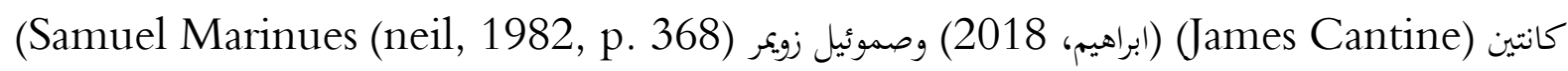

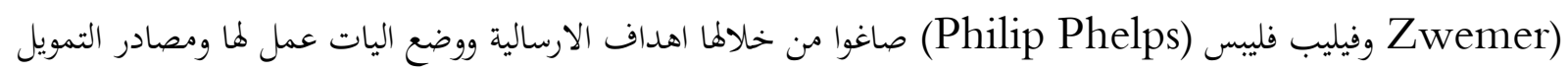

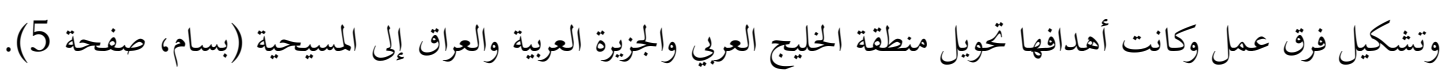
ابدت حكومة الولايات المتحدة الأمريكية اهتماماً ملحوظاً بالعراق منذ عام 1889، حين قررت تعيين أول قنصل لها في

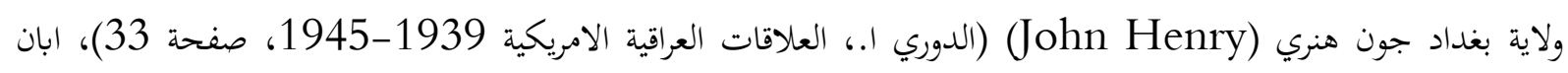

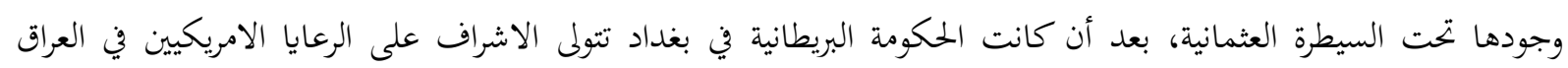

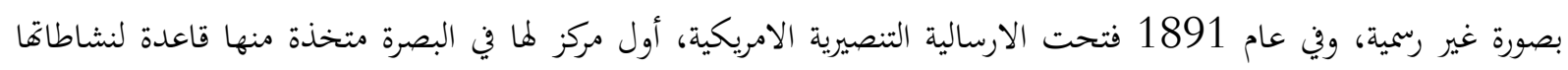
التنصيرية والثقافية في منطقة الخليج العربي، وفي اواخر عام 1895 وصل المنصرون إلى شمال العراق، متجهين نخو الميدانين الطبي

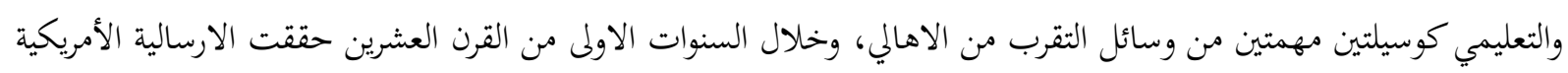

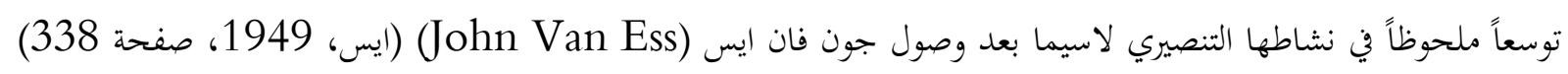

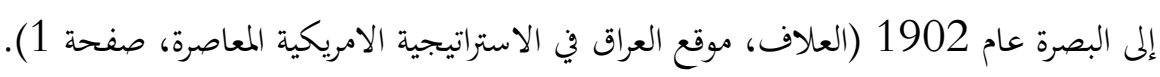

ساهم المنصرون الامريكيين وبشكل رئيسي في تغلغل نفوذ بلادهم في الدولة العثمانية والولايات التابعة ها، والى ذلك اشار

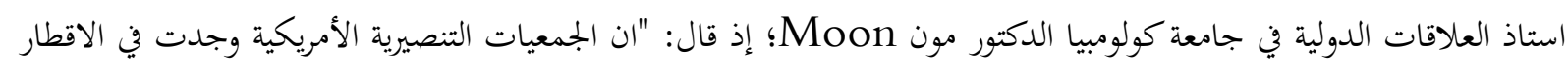
الخارجية من أجل بناء الامبراطورية " (Josef, 1961, p. 41).

ازداد الاهتمام الامريكي في العراق منذ اوائل القرن العشرين، إذ ارسلت الحكومة الامريكية، الادميرال الامريكي جستر

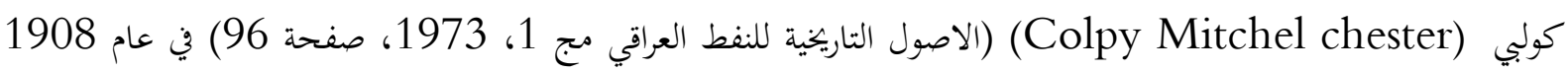


موفداً من قبل بجموعة من المستثمرين الامريكيين ليقود المفاوضات مع المسؤولين العثمانيين للحصول على الاسبقية في نفط الموصل

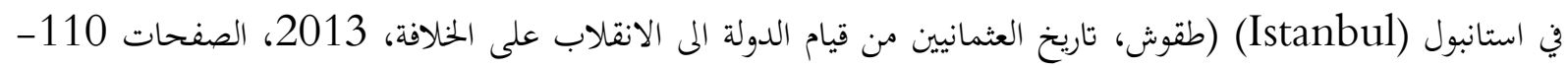

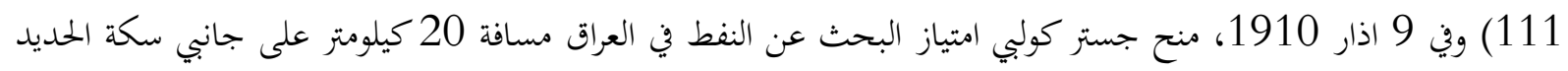

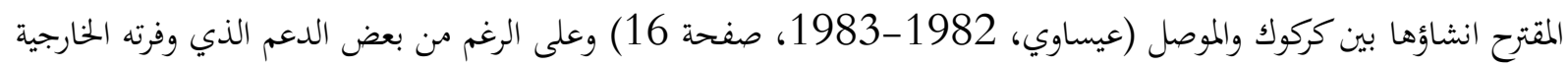

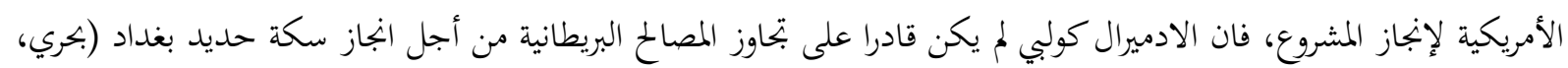
1967، الصفحات 69-72).

وبموجب اتفاقية سايكس بيكو (Sykes-Picot Agreement) (حسين، مشكلة الموصل دراسة في الدبلوماسية

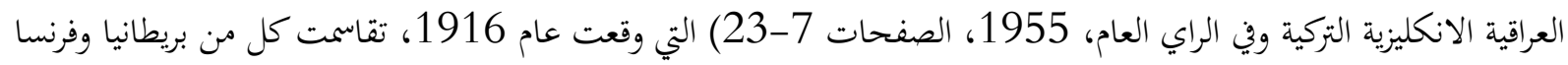
الأراضي العربية إذ حصلت الدولتان بموجب ذلك على حصة من نفط العراق، وقد اغضب ذلك الك الاتفاق الحكومة الإنبة الأمريكية لأنه

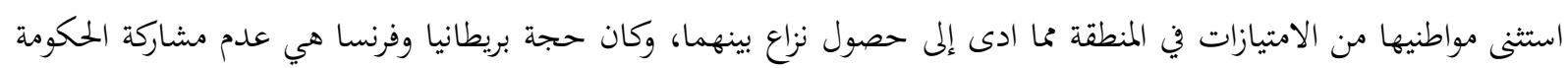

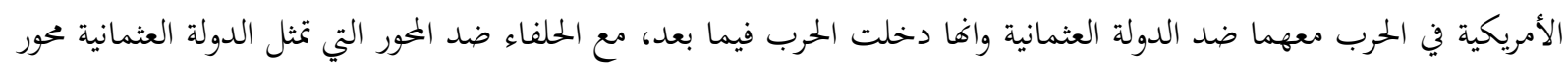
اساس فيها (الحمود، 1980، الصفحات 24-25)

امتعضت الولايات المتحدة الأمريكية من سياسة بريطانيا في العراق، هذا مع أن الرئيس الامريكي ودرو ولسن (1921-1913) (Woodrow Wilson) المتخلفة وفي 28 حزيران 1919 تشكلت عصبة الأمم بصورة رسمية واجتمع مجلس الحلفاء فوزعت المستعمرات الالمانية

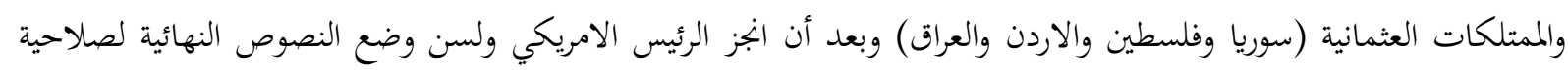

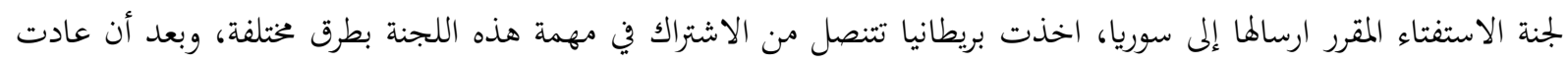

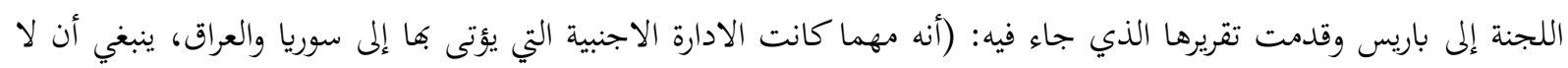

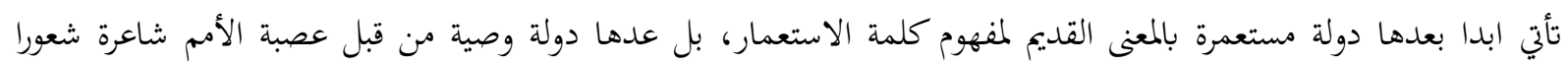

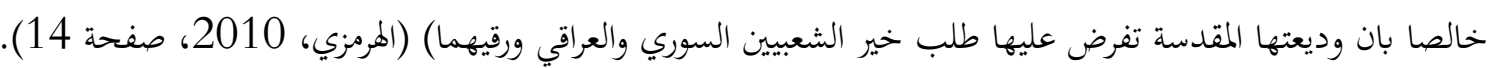
لذا طالبت الولايات المتحدة، من بريطانيا بضرورة اشراكها بنفط العراق والخليج العربي، لكن بريطانيا رفضت ذلك مما دفع الرئيس الامريكي ولسن (167-Academic American Encyclopedia, 1981, pp. 166) إلى ارسال

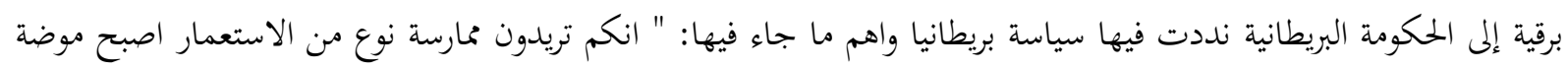

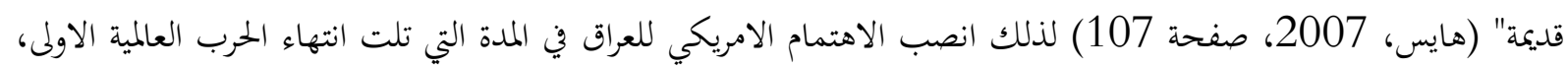

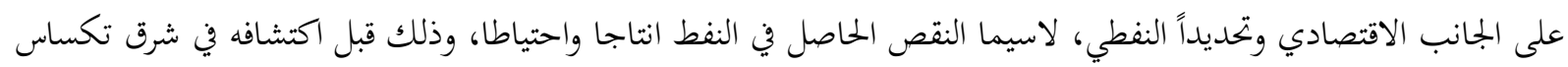

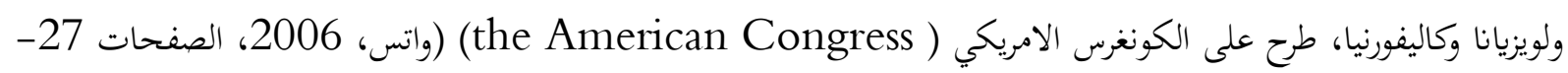
28) اقتراحاً لمعالجة ذلك النقص عبر تقييد تصدير النفط الخام والسيطرة على مصادر أخرى خارجية، ومساعدة الشركات الأمريكية في بلوغ هذا الهدف.

وعلى اثر ذلك تشكلت مجموعة شركات نفطية مكونة من (سكوني فاكوم Socony Facum، شركة تكساس

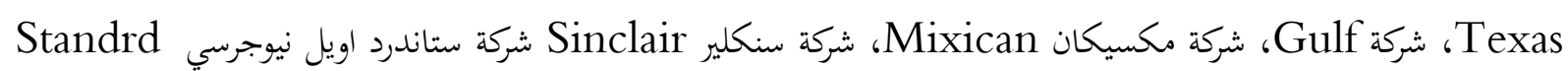
(Atlantic وإذ عقد اجتماع بين مدراء تلك الشركات انذاك مع المستشار التجاري في وزارة الخارجية الأمريكية للبحث في سبل تفعيل عمل هذه الشركات، على اساس مبدأ المشاركة الأمريكية في استثمار

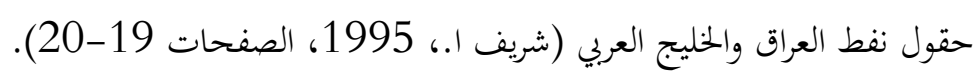


على أثر ذلك قامت شركة سكوني (socony) الأمريكية بإرسال بعثة من الجيولوجيين إلى العراق للبحث والتحري عن

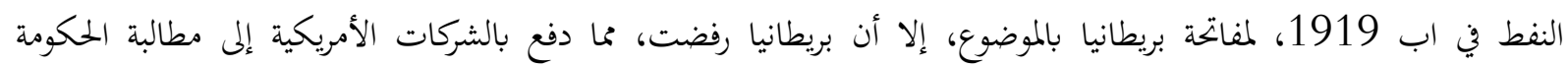

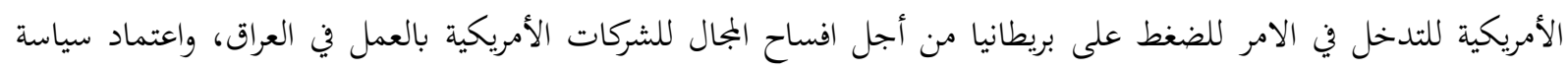

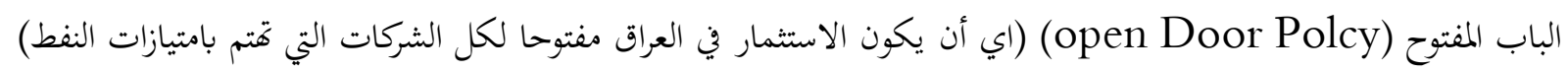

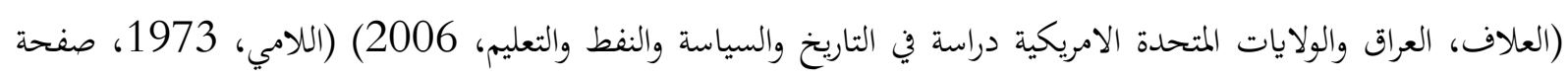
63) تمف من وجهة نظر الحكومة الأمريكية (الشرقاوي، صفحة 6) الحفاظ على حقوقها في الأراضي المسلوخة عن الدولة العثمانية والموضوعة تحت الانتداب.

وقد أصرت وزارة الخارجية الأمريكية على رفض العودة إلى أوضاع ما قبل الحرب (العكيدي ب.، صفحة 40) وذلك

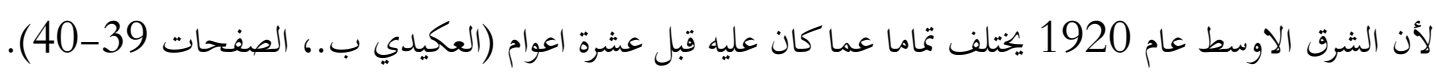
وبعد انعقاد مؤتمر لوزان (Lausanne conference) (عباس، 2014، صفحة 28) عام 1922، رأت بريطانيا أنه من الافضل لها اشراك الشركات الأمريكية لتحصل على تأييدها في مواجهة ادعاءات الدولة العثمانية في الموصل (حسين،

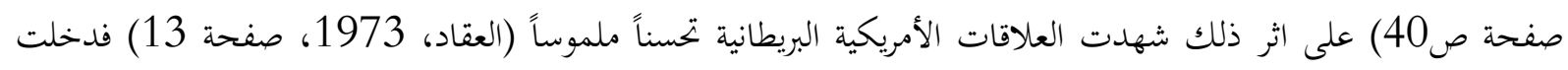

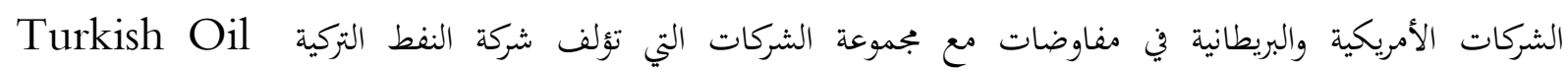
Company (خليل، 1979-1980، الصفحات 26-27) تمخضت المفاوضات عن عقد اتفاقية في 20 حزيران 1922، والخاصة بالمصالح الأمريكية البريطانية المتعلقة بموضوع نفط العراق وتتلخص بالاتي: لا يعترف بشركة النفط التركية إلا

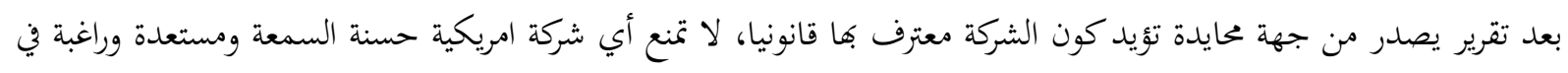

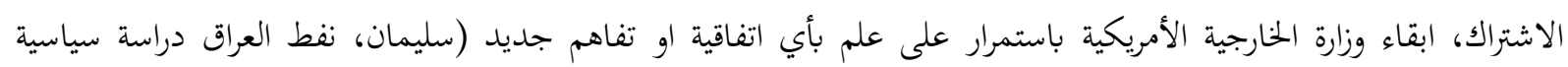

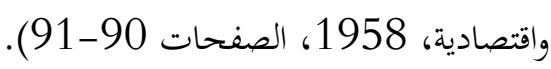

وبعد مفاوضات سرية دامت بين الحكومتين البريطانية والامريكية امتدت حتى عام 1926، انتهت بمنح الشركات

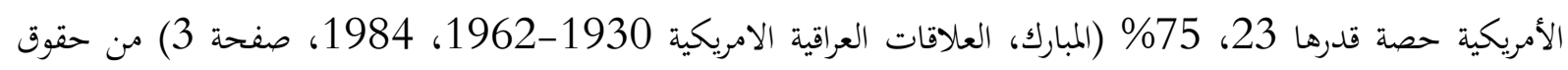

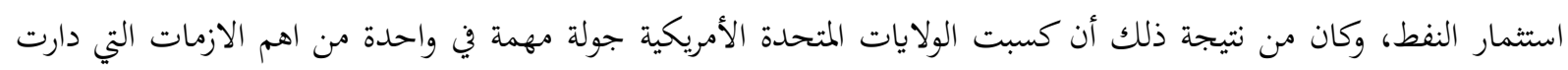

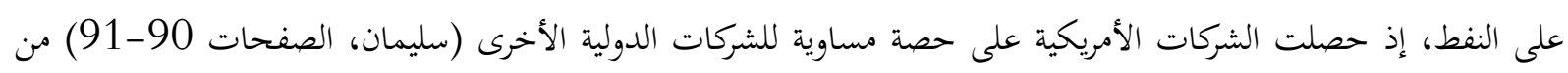

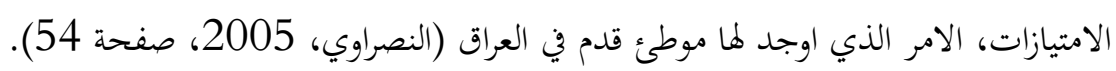

وعقب الاتفاقية التي وقعت بين شركة النفط التركية والحكومتين الأمريكية والبريطانية، وعلى اثر الاكتشافات النفطية

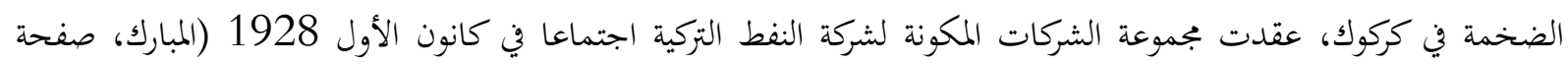

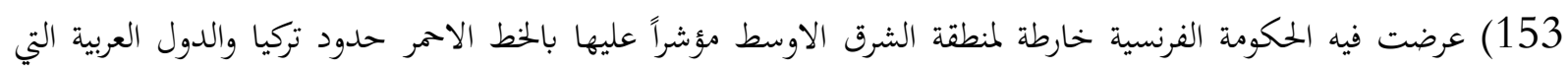

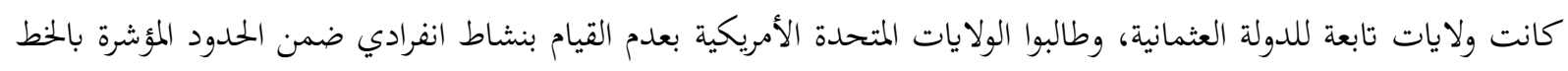
الاحمر (الغريري، 2013، الصفحات 23-24) إلا عن طريق شركة النفط التركية فوافقت الولايات المتحدة الأمريكية على كل

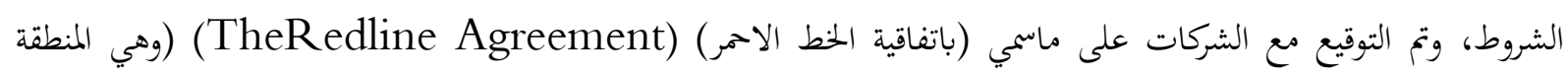

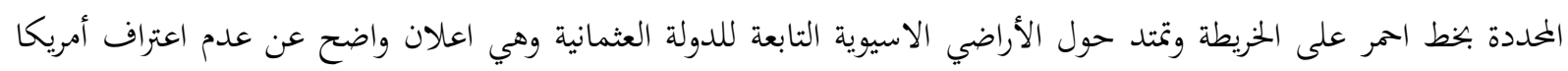
بالاتفاقية التي استبعدت الشركات النفطية الامريكية. وتم تاسيس كارتل يمارس نشاطه داخل المنطقة المحددة بخط احمر على الخارطة) (وهيم، 1982، الصفحات 106-

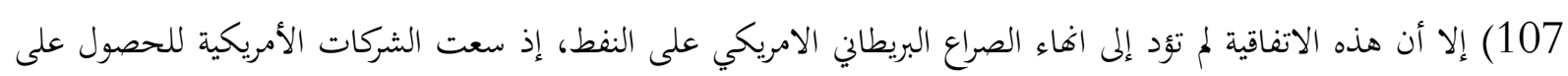


امتيازات نفطية منذ مطلع الثلاثينات من القرن العشرين، إذ ارادت أن تضع لها موطئ قدم في شركة نفط الموصل (سليمان،

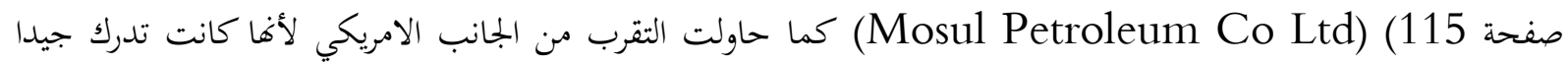
الامكانيات المالية الكبيرة التي تتمتع بها حكومة الولايات المتحدة (مراد، 1995، صفحة 82). من جانب اخر سعت الولايات المتحدة الأمريكية حثيثاً من أجل تطوير علاقاتها الدبلوماسية مع العراق، لما كان له من

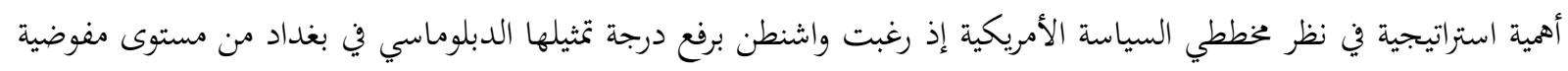

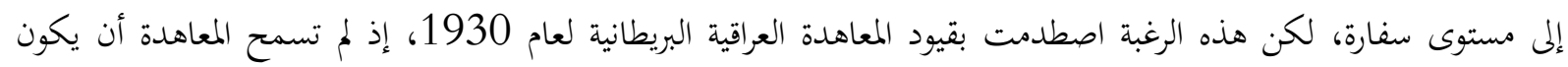

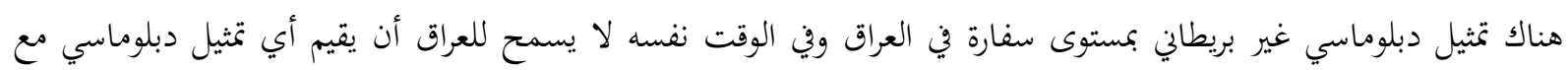
دولة أخرى، وان كانت بريطانيا على مستوى سفارة.

لذلك أبدت الولايات المتحدة استياءها الشديد لهذه الهيمنة البريطانية المفروضة على سياسة العراق الخارجية بموجب

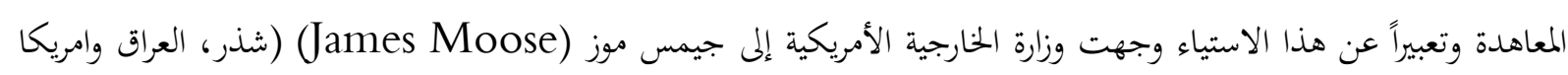
1945-1958، 1998، صفحة 102) انتقاد لما جاء في معاهدة 1930 من بنود تحول دون امكانية تطوير العلاقات

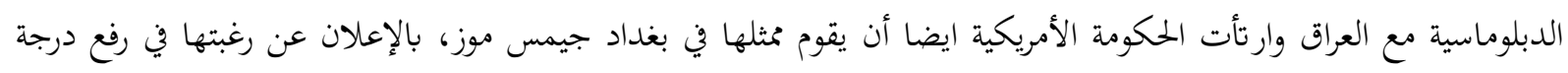

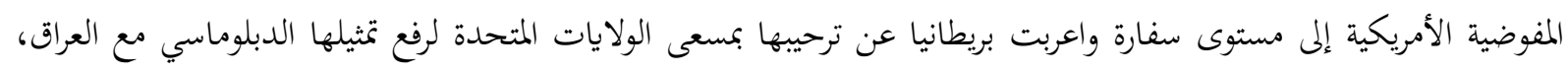

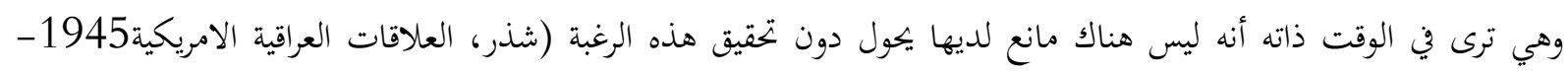

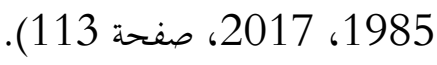

تطلب بجمل هذه التطورات في العلاقات القائمة بين العراق والولايات المتحدة الأمريكية تنظيم شؤوها في اطار معاهدات

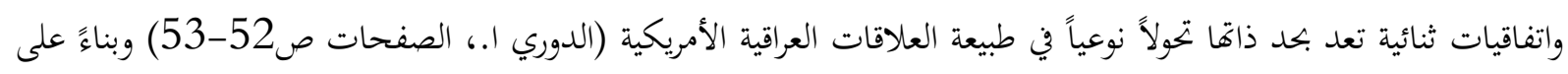
ذلك، جرت مفاوضات بين الحكومتين البريطانية والامريكية بخصوص اعداد لائحة تمهيدية لمعاهدة أرادت بريطانيا من خلالها، انتزاع اعتراف واشنطن بالانتداب البريطاني على العراق، فيما ارادت واشنطن وسيلة لاعتراف قطعي بحقوق الحكومة الأمريكية

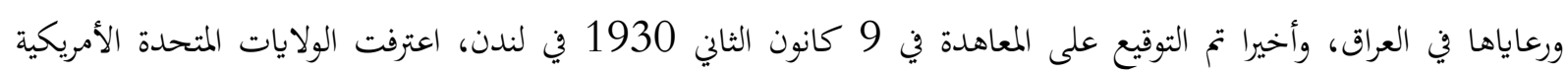

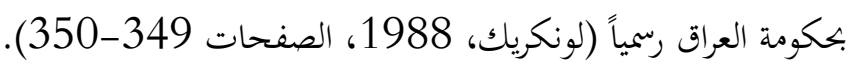

الامر الذي قيمه الملك فيصل بن الحسين في رده على المعتمد السامي البريطاني السير فرنسيس هنري همفريز Francis (Henry Humphries)

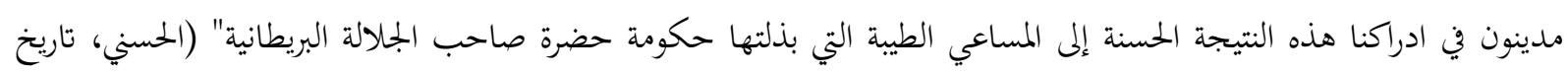

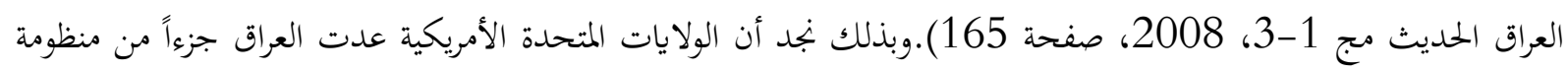

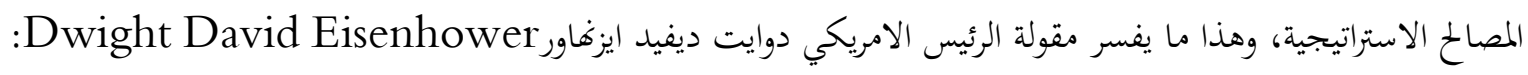

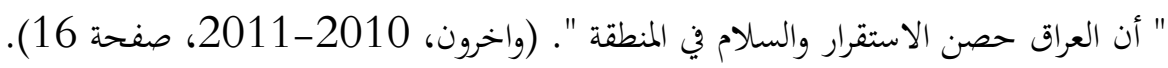




\section{المبحث الثالث: دور الولايات المتحدة الأمريكية في دخول العراق العصبة}

من الوسائل التي اعتمدقا الولايات لتأكيد تواجدها في العراق هو الجانب الثقافي لاسيما التعليمي منه، إذ طرأ على

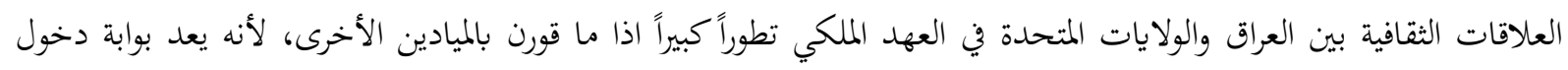

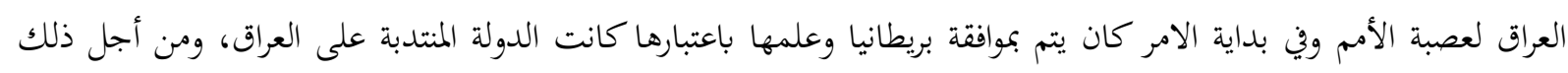

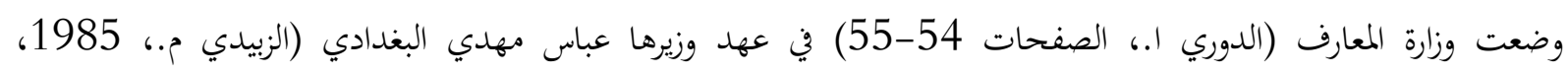

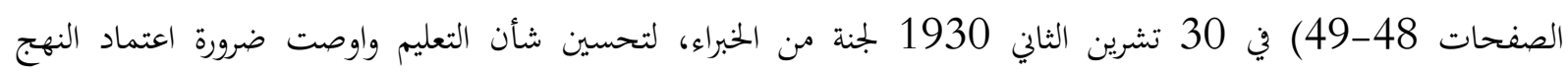

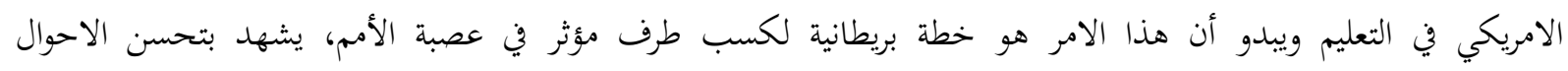

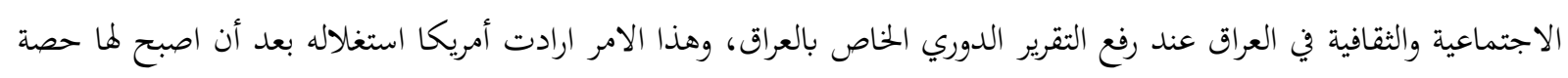

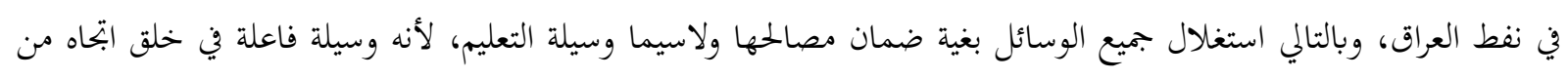

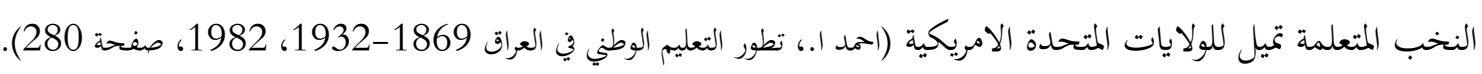
استغل السياسيون وفي مقدمتهم نوري السعيد التعليم في ادخال العراق كعضو في عصبة الأمم، لذلك استقر الامر على

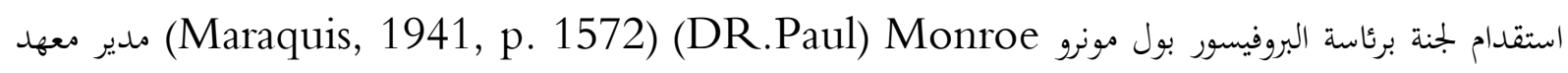

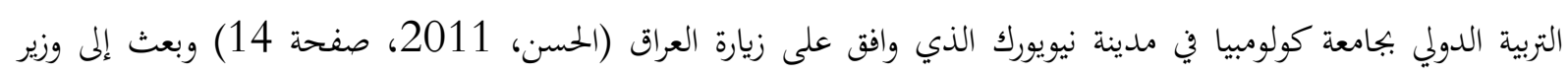
المعارف السابق الذكر، بكتاب يخبره بوصول اللجنة في اوائل شباط 1932 وكانت مؤلفة من: بول مونرو (P.Monrroe)

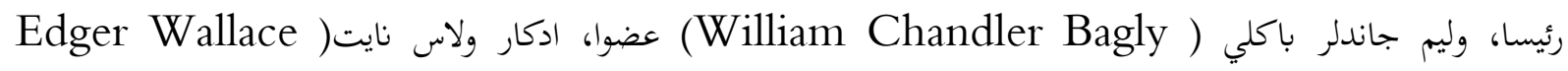
(Kinght ورافق اللجنة رسميا المفتش العام محمد فاضل الجمالي (احمد ا.، صفحة 313) الذي عاد إلى العراق مع اللجنة بعد حصوله على الدكتوراه في التربية من كلية المعلمين (Teachers College) في جامعة كولومبيا في السنة ذاتما. بدأت اللجنة عملها بان قدمت مقترحات عديدة لرفع مستوى التعليم وحل مشاكله ومن ذلك: تحسين أوضاع المعلمين، معالجة مشكلة الرسوب، ايجاد نوع من المدارس التي تسمى بمدارس التعليم بالعمل وذلك لمعالجة

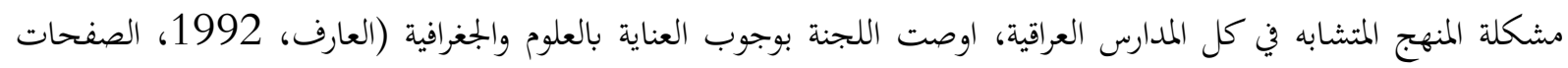

كان من اسباب استقدام لجنة مونرو هو رغبة الحكومة العراقية بتسجيل تطور كبير في ميدان التعليم (د.ك.و،الوحدة

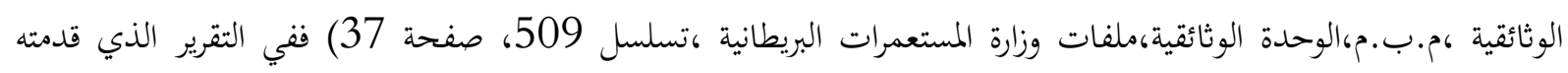

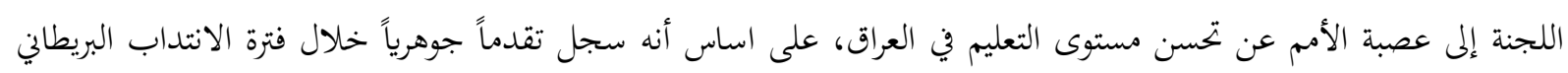
(احمد ا.، صفحة 333).

لقد تمثل الاتحاه الامريكي في التعليم، في قيام الحكومة العراقية بعقد مؤتمرها التربوي الأول في بغداد بين 9-15 نيسان 1932 برعاية الملك فيصل وقد حضر المؤتمر حوالي 70 بالمائة من العاملين في ميدان التربية والتعليم في العراق، افتتح المؤتمر في 9

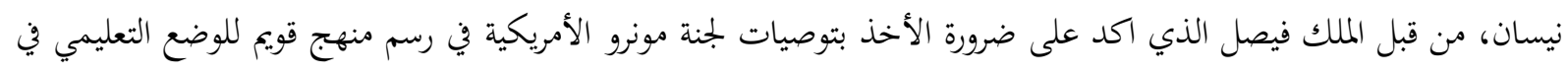

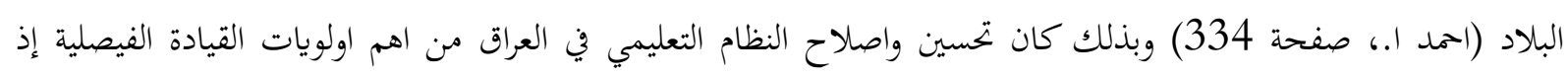
انصب التركيز على النهوض بالتعليم كعلاج لمختلف المشاكل الاجتماعية والاقتصادية في البلاد.

لقد كان من نتائج التوجه الامريكي افساح المجال للبعثات التنصيرية الأمريكية في انشاء عدد من المؤسسات التعليمية في

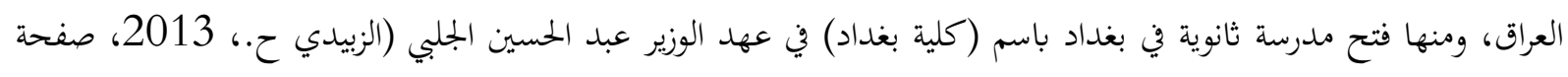


373) وترجع بدايات الدعوة لتأسيس هذه المدرسة إلى قيام الاب ادموند ولش (Admund Walsh) أحد اساتذة جامعة جورج تاون الأمريكية بزيارة العراق وذلك لغرض دراسة احوات التوعال التعليم في المدارس الكاثوليكية (تاريخ التعليم في العراق في عهد

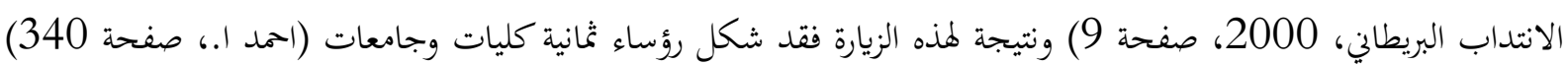

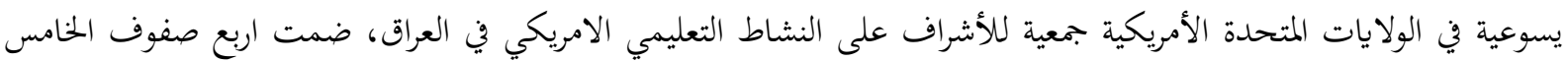

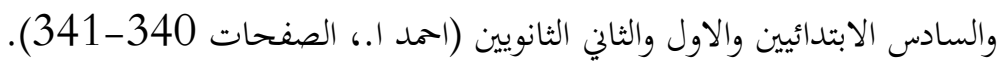

تتابع بعد ذلك وصول عدد من الخبراء الامريكيين التربويين إلى العراق منهم الخبير جورج كلوس (George Claus)

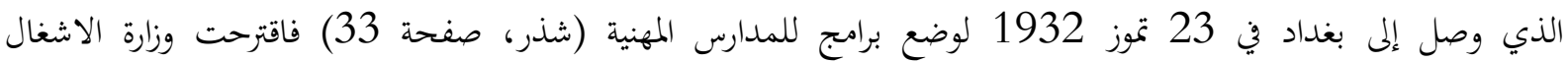
والمواصلات على مجلس الوزراء أن تستقدم خبيرا اجنبياً لادارة شؤون مدرسة الهندسة بهدف "اصلاحها وتطويرها لتكون معققة للرغائب والغايات المبتغاة منها (د.ك.و،الوحدة الوثائقية ، م.ب.م،مقررات مجلس الوزراء، مقررات شهر كانون اول 1924، صفحة 1). كما اقترحت وزارة المعارف في 7 ايلول 1932 على بجلس الوزراء تأليف لجنة لإصلاح المدارس الصناعية، على أن يرأس

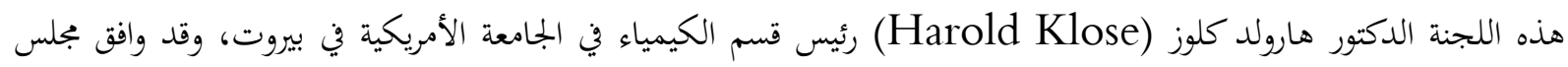

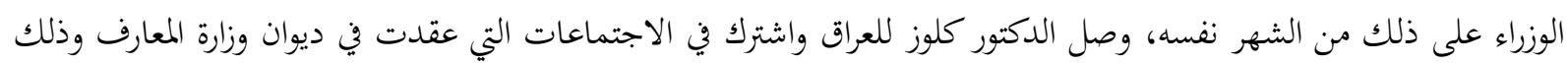

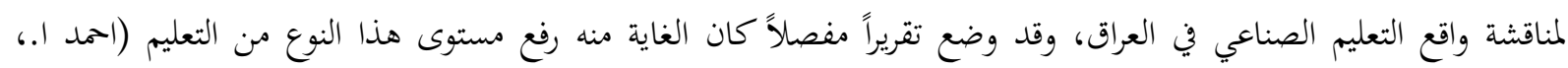
صفحة 342).

كما قدم الدكتور كالفن ستاوت (Clavins Staudt) طلباً لفتح مدرسة للبنين في بغداد وتمت الموافقة عليها، ومما

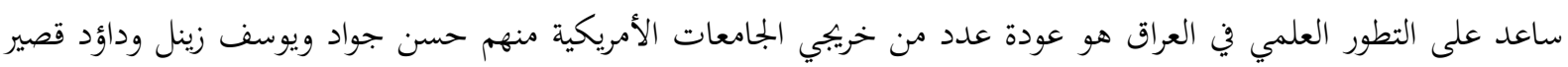

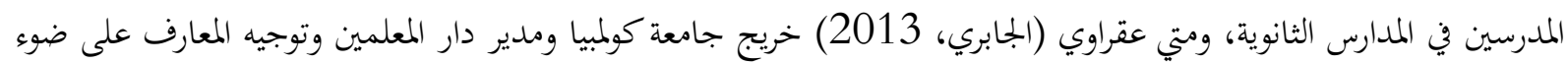

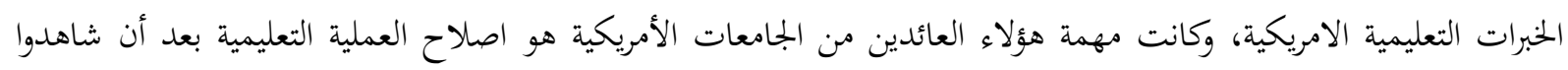

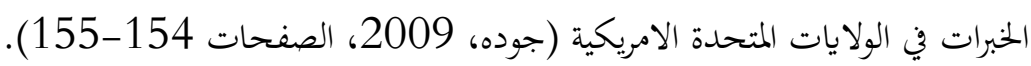
وكان للتقارير التي ارسلتها اللجان الأمريكية الخاصة بتطوير التعليم بالغ الاثر على موافقة مجلس العصبة على قبول العراق

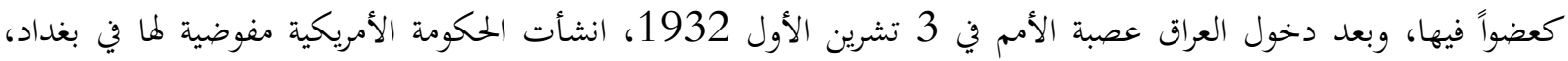

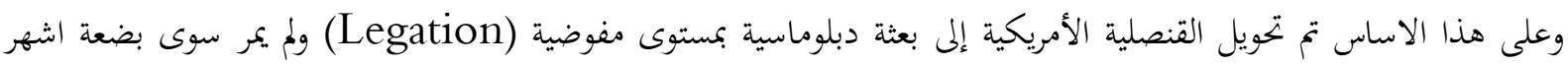

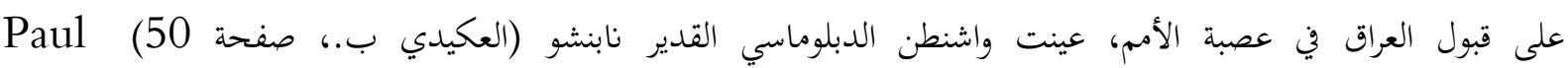
وزيراً مفوضاً لدى العراق، وكان ذلك بمثابة تحول نوعي في العلاقات العراقية الامريكية، لا سيما وان (Knabenshue)

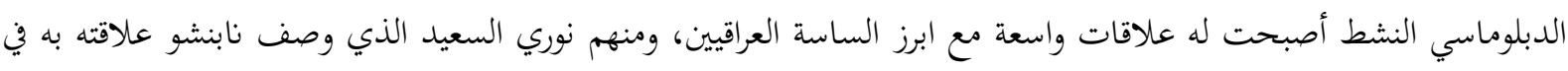

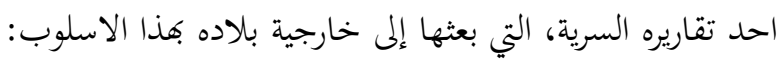
"انني ولحسن الحظ اتمتع بصداقة شخصية متينة مع نوري باشا، وعلى نطاق واسع من أي شخصية رسمية عراقية أخرى. اننا نتبادل الضيافة والزيارات على الدوام وهو يأتي إلى المفوضية للعب التنس، وفي الصيف الماضي علمته السباحة. انني اشعر بحرية

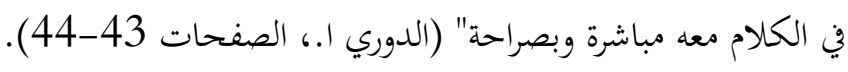
لقد شهدت الحقبة التاريخية التي اعقبت انضمام العراق إلى عصبة الأمم وما بعدها، تطورات سياسية واقتصادية واجتماعية تركت اثرها الواضح على مستوى التعليم فقد شهدت انعطافه جديدة في تاريخ التعليم ونقطة تحول ملموسة في مسيرته، فقد

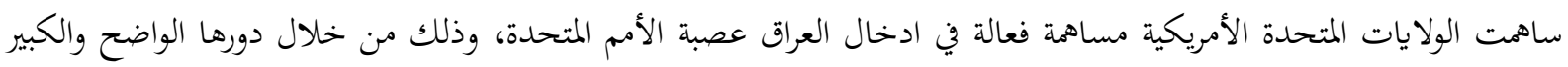


في النهوض بواقع العملية التربوية في العراق، وبذلك يكون للولايات المتحدة الأمريكية الدور الرائد والبارز في دخول العراق عصبة الأمم.

وبموجب الاحصاءات الرسمية العراقية بلغ عدد المدارس الأمريكية في العراق خلال العام الدراسي 1932-1933 ثماني

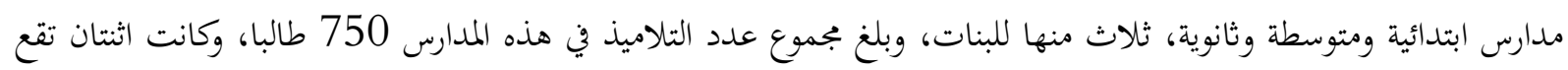

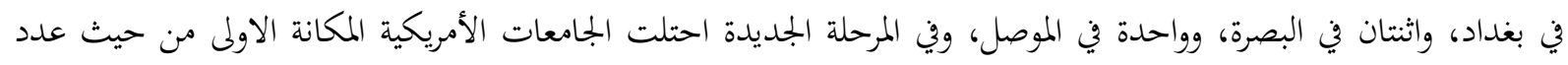

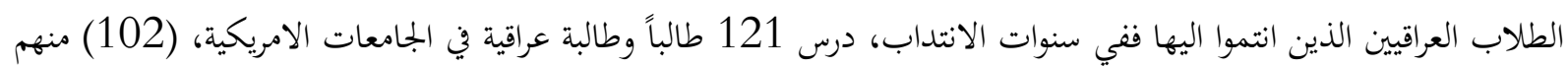

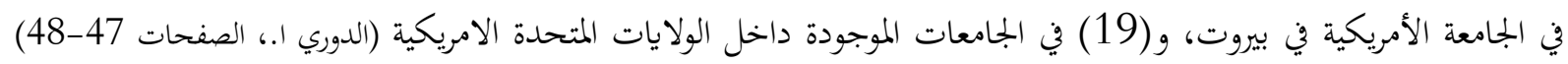

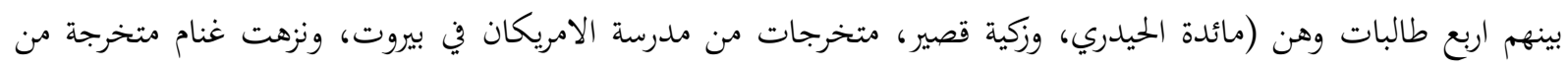

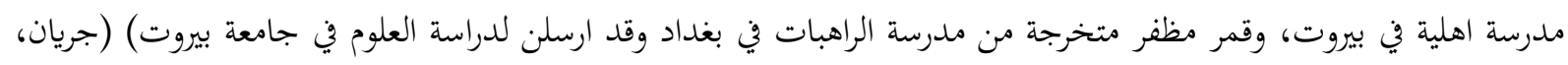
2005، صفحة 953)، ارتفع هذا العدد بعد دخول العراق عصبة الأمم المتحدة إلى (54) طالباً وطالبة، يدرسون في فئ الولايات المتحدة الامريكية.

ادناه جدول احصائي لطلبة البعثات العراقية إلى الولايات المتحدة الامريكية (زكي، 2013، صفحة 56)

\begin{tabular}{|c|c|}
\hline 5 & $1926-1925$ \\
\hline 4 & $1927-1926$ \\
\hline 3 & $1928-1927$ \\
\hline 3 & $1929-1928$ \\
\hline 1 & $1930-1929$ \\
\hline 4 & $1931-1930$ \\
\hline 5 & $1932-1931$ \\
\hline 19 & $1933-1932$ \\
\hline
\end{tabular}

وكان نتيجة الانفتاح على العالم الخارجي وارسال البعثات إلى الولايات المتحدة الأمريكية والاطلاع على مستوى التطور الذي شهده التعليم النسوي، فقد دعا الملك فيصل الاول، إلى تحرير المرأة وتعليمها وتثقيفها، مؤكدا على أن المرأة كلما ازدادت

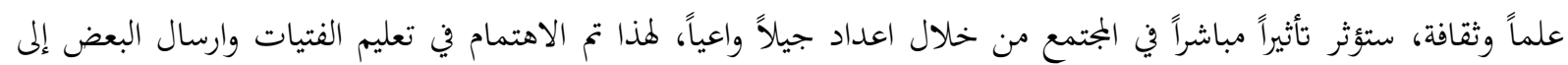

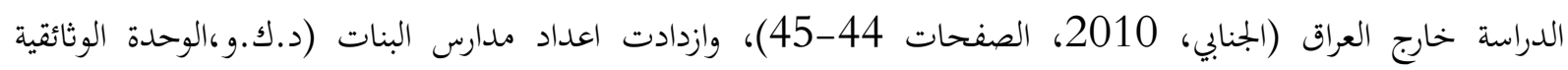

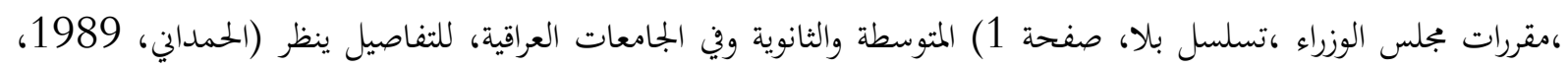
صفحة 80). وذلك بفضل السياسة التعليمية التي انتهجتها الحكومات العراقية وزيادة التخصيصات المالية في ميزانية الدولة لوزارة المعارف. 
يتبين لنا أن الولايات المتحدة الأمريكية سعت جاهدة ومنذ تغغغلها في العراق لجعله تابعاً لما، عن طريق السيطرة على

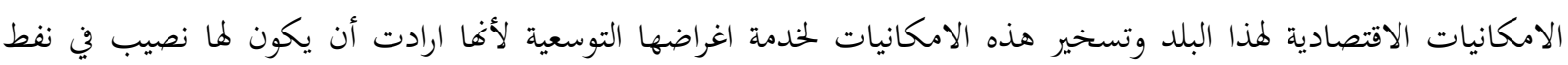
العراق، وقد اتضحت هذه المصالح في ميادين عدة سيما التعليم.

وهكذا استطاع الامريكيون انشاء مصالح اقتصادية وبحارية لمم في العراق خلال الفترة التي تلت الحرب العالمية الاولى، والتي كانت مليئة بالصراعات الدولية والتنافسات في منطقة الخليج العربي سيما العراق، وكيف استطاعت الولايات المتحدة الأمريكية

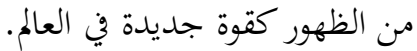


Academic American Encyclopedia. (1981). new jersy: Arete publishing company.

Albert Nelson Maraquis. (1941). whoss aho in America .chicago: the A.N.Marquis.

Bailey sydney D . Pprliamentary Macdonald J. Ramsay The Socialst Movement. colins conices Encyclopedia. (1985). london.

H.E.Egerton. (1923). The Causes and character of the American Revolution .london.

Jhon Josef. (1961). The Nestoriuns and the Muslims Neighbors princeten.

Stephen neil. (1982). AHistory of Christian Mission .London.

$$
\begin{aligned}
& \text { ابراهيم السامرائي. (2015). العراق البلد الذي نخره السياسيون 1914-2003. دار المعتز للنشر. } \\
& \text { ابراهيم خليل احمد. (بلا تاريخ). } \\
& \text { ابراهيم خليل احمد. (بلا تاريخ). } \\
& \text { ابراهيم خليل احمد. (بلا تاريخ). } \\
& \text { ابراهيم خليل احمد. (بلا تاريخ). } \\
& \text { ابراهيم خليل احمد. (بلا تاريخ). } \\
& \text { ابراهيم خليل احمد. (بلا تاريخ). }
\end{aligned}
$$

ابراهيم خليل احمد. (1982). تطور التعليم الوطني في العراق 1869-1932. البصرة: منشورات مركز دراسات الخليج العربي. ابراهيم خليل العلاف. (2006). العراق والولايات المتحدة الأمريكية دراسة في التاريخ والسياسة والنفط والتعليم. الموصل: مركز

$$
\text { الدراسات الاقليمية العدد السابع. }
$$

ابراهيم خليل العلاف. (بلا تاريخ). موقع العراق في الاستراتيجية الأمريكية المعاصرة. العراق: مركز الدراسات الاقليمية. ابراهيم شريف. (1995). الشرق الاوسط دراسة الاتحاهات وسياسة الاستعمار حتى قيام ثورة 14 تموز 1958 في العراقيه العراق.

$$
\text { بغداد: دار الجمهورية. }
$$

ابراهيم عكاشه علي. (1987). ملامح عن النشاط التنصيري في الوطن العربي. السعودية: جامعة الامام محمد بن سعود.

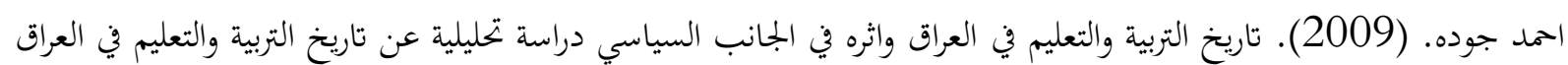

$$
\text { 1534-2009. بغداد: جعفر العصامي للطباعة الفنية الحديثة. }
$$$$
\text { احمد عطية الله. (1968). القاموس السياسي (المجلد ط3). القاهرة. }
$$

ادمون رباط. (2010). تطور سوريا السياسي في ظل الانتداب. (سليمان رياشي، المترجمون) بيروت: المركز العربي للابحاث

$$
\text { ودراسة السياسات. }
$$

اديث واي اف بينروز. (بلا تاريخ). العراق دراسة في علاقاته الخارجية وتطوراته الداخلية 1915-195. (عبد المجيد حسين

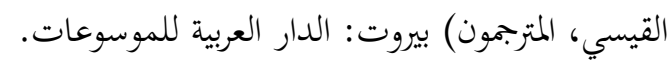

ارشد مزاحم مجبل الغريري. (2013). تطور العلاقات العراقية الامريكية. عمان: مركز الكتاب الاكاديمي.

اسامه الدوري. (بلا تاريخ).

اسامه عبد الرحمن الدوري. (بلا تاريخ).

اسامه عبد الرحمن نعمان الدوري. (بلا تاريخ).

اسامه عبد الرحمن نعمان الدوري. (بلا تاريخ).

اسامه عبد الرحمن نعمان الدوري. (بلا تاريخ). 
اسامه عبد الرمن نعمان الدوري. (بلا تاريخ).

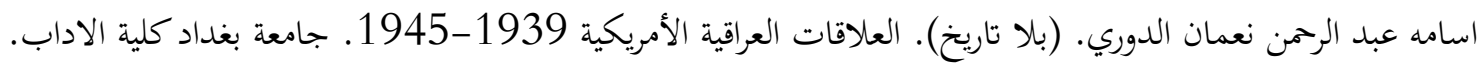
الاصول التاريخية للنفط العراقي مج 1. (1973). وزارة الاعلام مديرية الثقافة العامة.

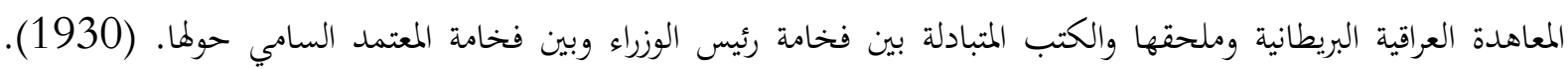

$$
\text { بغداد: مطبعة الحكومة. }
$$

اياد علي ياسين سرحان. (2001). بواكير النشاط الامريكي في العراق حتى عام 1921 رسالة ماجستير. جامعة الموصل كلية

$$
\text { التربية. }
$$

$$
\text { بشينة عباس الجنابي. (2010). الدور السياسي والاجتماعي لسيدات العهد الملكي في العراق. بغداد. }
$$

بشار فتحي جاسم العكيدي. (بلا تاريخ). صراع النفوذ البريطاني الامريكي 1939-1958 دراسة تاريخية سياسية رسالة

$$
\text { ماجستير. جامعة الموصل كلية التربية. }
$$

تاريخ التعليم في العراق في عهد الانتداب البريطاني. (2000). مجلة افاق عربية.

جاسم محمد هايس. (2007). العلاقات العراقية الأمريكية وتاثير النفط فيها. (جامعة البصرة كلية الدراسات التاريخية، المحرر) مجلة الخليج العربي المجلد الخامس والثلاثون.

جواد كاظم البكري واخرون. (2010-2011). العلاقات العراقية الأمريكية بحث منشور في كتاب التقرير الاستراتيجي العراقي.

$$
\begin{aligned}
& \text { بغداد: مركز حمورابي للبحوث والدراسات. } \\
& \text { جون فان ايس. (1949). اقدم اصدقاءي العرب. (جميل عمسو، المترجمون) بغداد. } \\
& \text { حسن لطيف الزبيدي. (2013). موسوعة السياسة العراقية. بيروت: العارف للمطبوعات. } \\
& \text { حسين طعمه شذر. (بلا تاريخ). }
\end{aligned}
$$

حسين طعمه شذر. (1998). العراق وامريكا 1945-1958. (2017) دار الملتقى.

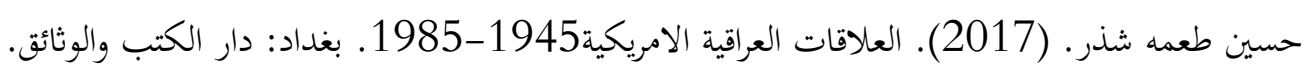

$$
\text { حكمت سامي سليمان. (بلا تاريخ). }
$$

حكمت سامي سليمان. (1958). نفط العراق دراسة سياسية واقتصادية. دمشق: دار اليقظة.

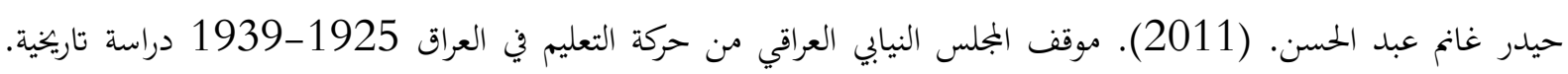

$$
\text { جامعة الكوفة كلية الاداب. }
$$

$$
\text { خالد بسام. (بلا تاريخ). ثرثرة فوق غر دجلة. عمانة. }
$$

خليل علي مراد. (1995). نشاة المصالح الأمريكية في نفط العراق. ندوة تاريخ الاطماع الأمريكية في العراق نظمتها جمعية

$$
\text { المؤرخين العراقية فرع نينوى. }
$$

د.ك.و، الوحدة الوثائقية، م.ب.م، مقررات مجلس الوزراء. (مقررات شهر كانون أول 1924). تسلسل بلا. كتاب وزارة الاشغال والمواصلات إلى سكرتارية مجلس الوزراء المرقم 7340 في 4 كانون أول 1924 المتضمن استقدام المستر الفرد 
د.ك.و، الوحدة الوثائقية، م.ب.م، الوحدة الوثائقية، ملفات وزارة المستعمرات البريطانية، تسلسل 509. (بلا تاريخ). كتاب

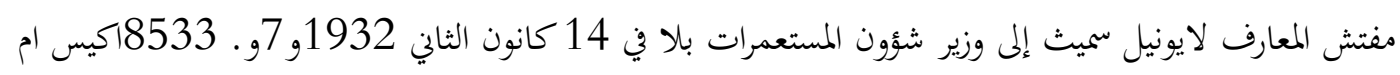

$$
\text { .69409/175/730 }
$$

د.ك.و، الوحدة الوثائقية، م.ب، م، مقررات مجلس الوزراء، تسلسل بلا. (بلا تاريخ). مقررات شهري حزيران وتموز سنة 1924،

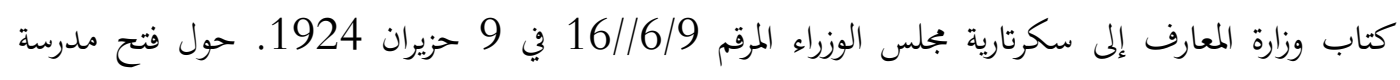

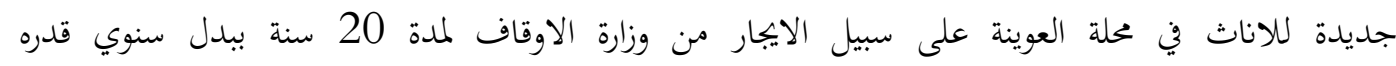

$$
\text { رونالد واتس. (2006). الانظمة الفيدرالية. كندا: منتدى الاتحادات الفدرالية. }
$$
زينب هاشم جريان. (العدد4, 2005). التعليم النسوي في العراق 1921-1958 دراسة تاريخية. مجلة كلية التربية للبنات المجلد 26

$$
\begin{aligned}
& \text { ستيفن همسلي لونكريك. (1988). العراق الحديث من سنة 1900-1950. بغداد: منشورات الفجر. } \\
& \text { سعاد رؤوف محمد. (1988). نوري السعيد ودوره في السياسة العراقية. بغداد: مكتبة اليقظة. } \\
& \text { سوسن جبار شريف. (بلا تاريخ). }
\end{aligned}
$$

سوسن جبار شريف. (2016). الخنليج العربي في السياسة الخارجية الامريكية شتريفية 1971-1988. سيف نصرت توفيق الهرمزي. (2010). الحرب الأمريكية على العراق الدوافع الاستراتيجية والابعاد الاقتصادية. بغداد: كلية

$$
\text { العلوم السياسية جامعة النهرين. }
$$

شارل عيساوي. (1982-1983). التطور التاريخي للعلاقات الاقتصادية الأمريكية العربية. (مركز البحوث والمعلومات، المحرر)

$$
\text { مجلة شؤون العرب الامريكية. }
$$

شعلة اسماعيل العارف. (1992). نظام التعليم في العراق. بغداد: دار الحكمة للطباعة والنشر.

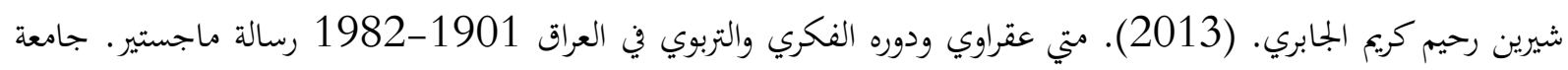
بغداد كلية الاداب.

صفاء عبد الوهاب المبارك. (بلا تاريخ). صفاء عبد الوهاب المبارك. (1984). العلاقات العراقية الأمريكية 1930-1962. (جامعة البصرة، المحرر) مجلة كلية التربية

$$
\text { للبنات العدد } 7 .
$$

صلاح العقاد. (1973). البترول اثره في السياسة الدولية والمجتمع. القاهرة.

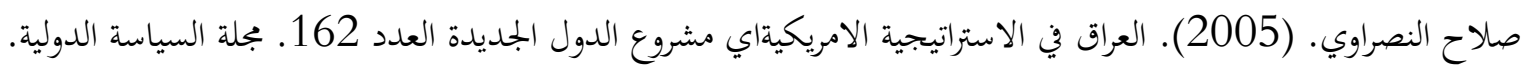

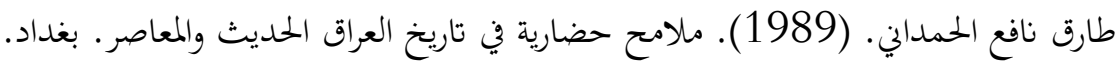

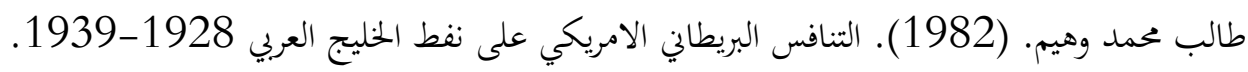

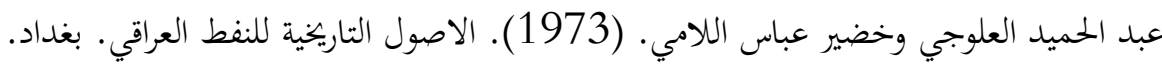

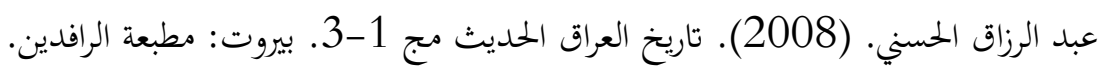

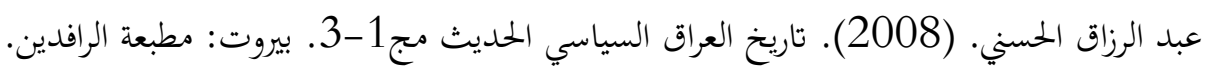

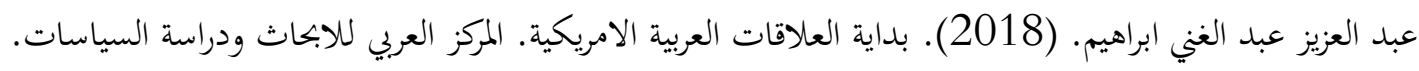

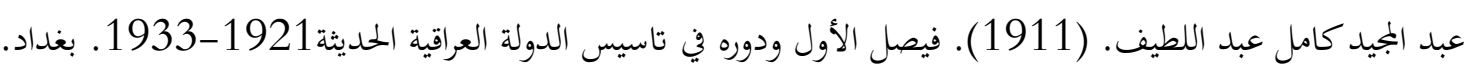

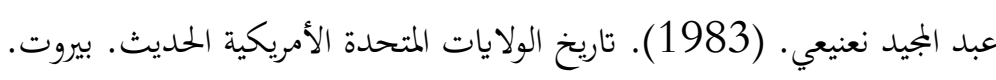


غازي دحام فهد الرسومي. (1986). التعليم في العراق 1932-1945 دراسة تاريخية. جامعة بغداد كلية الاداب.

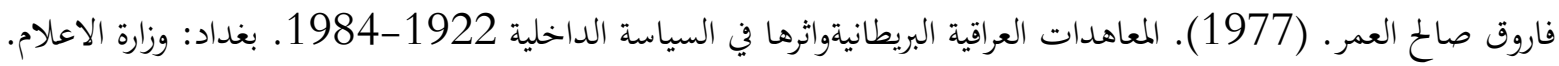
فاضل حسين. (بلا تاريخ). فاضل حسين. (1955). مشكلة الموصل دراسة في الدبلوماسية العراقية الانكليزية التركية وفي الراي العام. بغداد. فاضل عبد القادر احمد. (1989). صراع القوتين العظيمين في القسم الشرقي من البحر المتوسط بعد الحرب العالمية الثانية اطروحة دكتوراه. بغداد كلية الاداب.

فهد سعد الحمود. (1980). ثروات السعودية وسبيل الاستقلال الاقتصادي. بيروت: دار الفارابي. قرار مجلس عصبة الأمم. (بلا تاريخ). قرار مجلس عصبة الأمم ومذكراته. (بلا تاريخ). قرار مجلس عصبة الأمم ومذكراته بشان دخول العراق عصبة الأمم. (بلا تاريخ). قرار بجلس عصبة الأمم ومذكراته بشان دخول العراق عصبة الأمم. (بلا تاريخ). قرار مجلس عصبة الأمم ومذكراته بشان دخول العراق عصبة الأمم في اجتماعه المنعقد في 28 كانون الثاني 1932. 1932 (1932). بغداد: مطبعة الحكومة.

لؤي بحري. (1967). سكة حديد بغداد برلين بغداد حتى عام 1914. بغداد: شركة الطبع والنشر الاهلية.

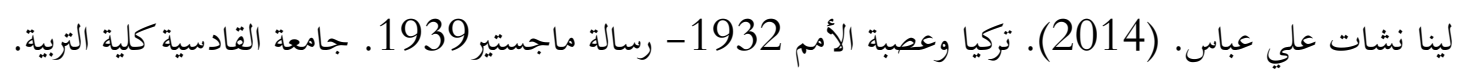

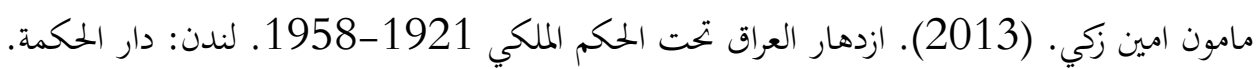
محمد حسين الزبيدي. (1985). العراقيون المنفيون إلى جزيرة هنجام. بغداد: دار الحرية.

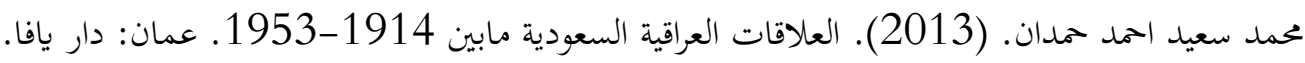
محمد سهيل طقوش. (2013). تاريخ العثمانيين من قيام الدولة إلى الانقلاب على الخنافة (المجلد ط3).

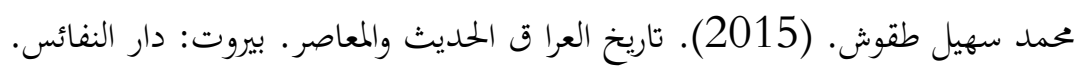
محمود الشرقاوي. (بلا تاريخ). أمريكا وبترول الشرق الاوسط. القاهرة.

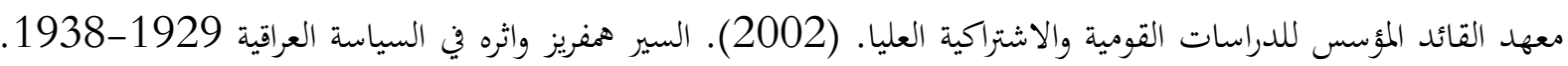

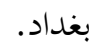
نجدة فتحي. (1988). مذكرات رستم حيدر. بيروت: الدار العربية للموسوعات. نسيم سوسه. (بلا تاريخ). نسيم سوسه. (بلا تاريخ).

نسيم سوسه. (بلا تاريخ). عصبة الأمم والعراق. بغداد: دار الطباعة الحديثة.

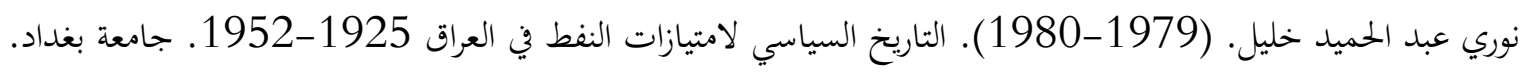

